Article

\title{
Dinuclear Lanthanide(III) Complexes from the Use of Methyl 2-Pyridyl Ketoxime: Synthetic, Structural, and Physical Studies
}

\author{
Christina D. Polyzou ${ }^{1}$, Helen Nikolaou ${ }^{1}$, Catherine P. Raptopoulou ${ }^{2}{ }^{10}$, Konstantis F. Konidaris ${ }^{3}{ }^{\circledR}$, \\ Vlasoula Bekiari ${ }^{4, *} \mathbb{1}$, Vassilis Psycharis $2, * \mathbb{C}$ and Spyros P. Perlepes ${ }^{1,5, *}$
}

1 Department of Chemistry, University of Patras, 26504 Patras, Greece; christipoche@gmail.com (C.D.P.); eleni.nikolaou-2@postgrad.manchester.ac.uk (H.N.)

2 Institute of Nanoscience and Nanotechnology, NCSR “Demokritos”, 15310 Aghia Paraskevi Attikis, Greece; c.raptopoulou@inn.demokritos.gr

3 Department of Pharmacy, University of Patras, 26504 Patras, Greece; konstantis.konidaris@gmail.com

4 Department of Crop Science, University of Patras, 30200 Messolonghi, Greece

5 Foundation for Research and Technology-Hellas (FORTH), Institute of Chemical Engineering Sciences (ICE-HT), Platani, B.O. Box 1414, 26504 Patras, Greece

* Correspondence: bbekiari@upatras.gr (V.B.); v.psycharis@inn.demokritos.gr (V.P.); perlepes@patreas.upatras.gr (S.P.P.); Tel.: +30-26130-58240 (V.B.); +30-210-6503346 (V.P.); +30-2610-996730 (S.P.P.)

\section{check for} updates

Citation: Polyzou, C.D.; Nikolaou, H.; Raptopoulou, C.P.; Konidaris, K.F.; Bekiari, V.; Psycharis, V.; Perlepes, S.P. Dinuclear Lanthanide(III) Complexes from the Use of Methyl 2-Pyridyl Ketoxime: Synthetic, Structural, and Physical Studies. Molecules 2021, 26, 1622. https://doi.org/10.3390/ molecules26061622

Academic Editor:

Nikolay Gerasimchuk

Received: 29 January 2021

Accepted: 9 March 2021

Published: 15 March 2021

Publisher's Note: MDPI stays neutral with regard to jurisdictional claims in published maps and institutional affiliations.

Copyright: (C) 2021 by the authors. Licensee MDPI, Basel, Switzerland. This article is an open access article distributed under the terms and conditions of the Creative Commons Attribution (CC BY) license (https:// creativecommons.org/licenses/by/ $4.0 /)$.

\begin{abstract}
The first use of methyl 2-pyridyl ketoxime (mepaoH) in homometallic lanthanide(III) $[\mathrm{Ln}(\mathrm{III})]$ chemistry is described. The 1:2 reactions of $\mathrm{Ln}\left(\mathrm{NO}_{3}\right)_{3} \cdot n \mathrm{H}_{2} \mathrm{O}(\mathrm{Ln}=\mathrm{Nd}, \mathrm{Eu}, \mathrm{Gd}, \mathrm{Tb}, \mathrm{Dy}$; $n=5,6)$ and mepaoH in MeCN have provided access to complexes $\left[\operatorname{Ln}_{2}\left(\mathrm{O}_{2} \mathrm{CMe}\right)_{4}\left(\mathrm{NO}_{3}\right)_{2}(\mathrm{mepaoH})_{2}\right]$ $(\mathrm{Ln}=\mathrm{Nd}, 1 ; \mathrm{Ln}=\mathrm{Eu}, 2 ; \mathrm{Ln}=\mathrm{Gd}, 3 ; \mathrm{Ln}=\mathrm{Tb}, 4 ; \mathrm{Ln}=\mathrm{Dy}, 5)$; the acetato ligands derive from the $\mathrm{Ln}^{\mathrm{III}}$-mediated hydrolysis of $\mathrm{MeCN}$. The 1:1 and 1:2 reactions between $\mathrm{Dy}\left(\mathrm{O}_{2} \mathrm{CMe}\right)_{3} \cdot 4 \mathrm{H}_{2} \mathrm{O}$ and mepaoH in $\mathrm{MeOH} / \mathrm{MeCN}$ led to the all-acetato complex $\left[\mathrm{Dy}_{2}\left(\mathrm{O}_{2} \mathrm{CMe}\right)_{6}(\mathrm{mepaoH})_{2}\right](6)$. Treatment of $\mathbf{6}$ with one equivalent of $\mathrm{HNO}_{3}$ gave 5 . The structures of 1,5 , and $\mathbf{6}$ were solved by single-crystal $\mathrm{X}$-ray crystallography. Elemental analyses and IR spectroscopy provide strong evidence that 2-4 display similar structural characteristics with $\mathbf{1}$ and $\mathbf{5}$. The structures of $\mathbf{1}-\mathbf{5}$ consist of dinuclear molecules in which the two $\mathrm{Ln}^{\mathrm{III}}$ centers are bridged by two bidentate bridging $\left(\eta^{1}: \eta^{1}: \mu_{2}\right)$ and two chelating-bridging $\left(\eta^{1}: \eta^{2}: \mu_{2}\right)$ acetate groups. The $\mathrm{Ln}^{\mathrm{III}}$ atoms are each chelated by a $N, N^{\prime}$-bidentate mepaoH ligand and a near-symmetrical bidentate nitrato group. The molecular structure of 6 is similar to that of 5 , the main difference being the presence of two chelating acetato groups in the former instead of the two chelating nitrato groups in the latter. The geometry of the 9-coordinate $\mathrm{Ln}^{\mathrm{III}}$ centers in 1, 5 and 6 can be best described as a muffin-type (MFF-9). The 3D lattices of the isomorphous 1 and 5 are built through $\mathrm{H}$-bonding, $\pi \cdots \pi$ stacking and $\mathrm{C}-\mathrm{H} \cdots \pi$ interactions, while the 3D architecture of 6 is stabilized by H bonds. The IR spectra of the complexes are discussed in terms of the coordination modes of the organic and inorganic ligands involved. The Eu(III) complex 2 displays a red, metal-ion centered emission in the solid state; the $\mathrm{Tb}^{\mathrm{III}}$ atom in solid 4 emits light in the same region with the ligand. Magnetic susceptibility studies in the $2.0-300 \mathrm{~K}$ range reveal weak antiferromagnetic intramolecular $\mathrm{Gd}^{\mathrm{III}} \cdots \mathrm{Gd}^{\mathrm{III}}$ exchange interactions in 3; the $J$ value is $-0.09(1) \mathrm{cm}^{-1}$ based on the spin Hamiltonian $\hat{\mathrm{H}}=-\mathrm{J}\left(\hat{\mathrm{S}}_{\mathrm{Gd} 1} \cdot \hat{\mathrm{S}}_{\mathrm{Gd} 2}\right)$.
\end{abstract}

Keywords: coordination chemistry; dinuclear lanthanide(III) complexes; magnetic properties of gadolinium(III) complexes; metal complexes of methyl 2-pyridyl ketoxime; photoluminescence studies; single-crystal X-ray structures

\section{Introduction}

Oximes are versatile organic molecules containing the $>\mathrm{C}=\mathrm{N}-\mathrm{OH}$ group, which have been extensively used as efficient reagents in analytical chemistry and as excellent ligands in inorganic chemistry. There are several types of oximes: aliphatic and aromatic 
monoximes derived from ketones $r$ aldehydes, $\alpha$-dioximes, and recently new families of amino/imido oximes and cyanoximes have attracted intense attention [1]. Although the nitroso-oxime tautomerism is known in solution, most solid compounds exist in their oxime form. One of the first uses of oximes in metal chemistry was the gravimetric determination of $\mathrm{Ni}$ (II) in the form of the red bis(dimethylglyoximato)nickel(II) [2], an experiment performed by undergraduate Chemistry students in most universities. Today, oxime and oximato metal complexes are central "players" in several aspects of coordination [3-5] and bioinorganic [6,7] chemistry, molecular magnetism [8-11], catalysis [12,13], and in the area of the reactivity of coordinated ligands [14-16].

A central theme in our research groups is the study of the coordination chemistry of 2-pyridyl oximes in which the substituent $\mathrm{R}$ at the oxime carbon is either a non-donor group (Figure 1) or a donor group (e.g., $\mathrm{R}=\mathrm{CN}, \mathrm{NH}_{2}$, 2-pyridyl, etc.) [17]. Restricting further discussion to the former family of ligands, the emphasis of our efforts (only selected references from our work are given below) has been on (a) the optical and magnetic properties of the resulting homo- and heterometallic dinuclear [18-21] and polynuclear [22-27] complexes, (b) the metal-mediated/promoted/assisted reactivity of these ligands [28-30], and (c) the modeling of the solvent extraction of toxic metal ions from aqueous solutions by 2-pyridyl ketoximes [31,32]. A literature survey reveals that a plethora of homometallic complexes of paoH, mepaoH, phpaoH, and ClpaoH (Figure 1), in their neutral or anionic forms, have been prepared and studied with transition [22-25,27-29,31,32] and actinide [21] metal ions. In contrast, with the exception of $\left[\mathrm{LnCl}_{3}(\mathrm{phpaoH})_{3}\right](\mathrm{Ln}=\mathrm{Nd}$ [33], Sm [34]), such complexes are not known in lanthanide (Ln) chemistry.

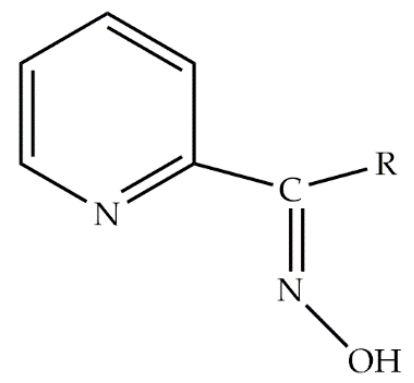

$$
\begin{aligned}
& \mathrm{R}=\mathrm{H} ; \text { paoH } \\
& \mathrm{R}=\mathrm{Me} ; \mathrm{mepaoH} \\
& \mathrm{R}=\mathrm{Ph} ; \text { phpaoH } \\
& \mathrm{R}=\mathrm{Cl} ; \text { ClpaoH }
\end{aligned}
$$

Figure 1. General structural formula of simple 2-pyridyl oximes, in which $\mathrm{R}$ is a non-donor group; the ligand used in the present work is methyl 2-pyridyl ketoxime $(\mathrm{R}=\mathrm{Me}$; mepaoH).

We have embarked on a new program aiming to fill the above-mentioned literature gap and prepare $4 \mathrm{f}$-metal complexes with the ligands (neutral or deprotonated) shown in Figure 1. In this work, which is the first of a series of papers on this topic, we report our preliminary results on the reactions of Ln(III) sources and methyl 2-pyridyl ketoxime (mepaoH; R = Me in Figure 1) in the absence of an external base. Our efforts have led to dinuclear Ln(III) complexes with interesting structural features and properties; a point of interest is that the bridging acetato ligands in most of the complexes have resulted from the $\mathrm{Ln}^{\mathrm{III}}$-assisted hydrolysis of the MeCN (solvent). This paper can also be considered as a continuation of the interest of our groups in the chemistry and properties (photophysical, magnetic, catalytic) of the $\mathrm{Ln}^{\mathrm{III}}{ }_{2}$ complexes [35-44]; such complexes can potentially combine both optical and magnetic properties within the same molecule leading to luminescent SMMs $[45,46]$. $\mathrm{Ln}^{\mathrm{III}}{ }_{2}$ compounds continue to attract the intense attention of many inorganic chemistry groups around the world because they are ideal model systems for providing answers to fundamental questions regarding the origin of a certain physical, spectroscopic, or catalytic property, i.e., if such properties arise from the whole molecule ( $t w o \mathrm{Ln}^{\mathrm{III}}$ centers) or half of it (a single $\mathrm{Ln}^{\mathrm{III}}$ ion) [47]. 


\section{Results and Discussion}

\subsection{Synthetic Comments}

A variety of $\mathrm{Ln}(\mathrm{III}) / \mathrm{X}^{-} / \mathrm{mepaoH}$ reaction systems involving various metal ions and $\mathrm{X}^{-}\left(\mathrm{X}^{-}=\mathrm{Cl}^{-}, \mathrm{NO}_{3}{ }^{-}, \mathrm{MeCO}_{2}{ }^{-}\right)$, and different solvent media, reagent ratios, and crystallization methods were systematically employed before arriving at the optimized procedures reported in Section 3. Since we were interested in obtaining products with the neutral oxime ligand, we avoided the addition of an external base, e.g., $\mathrm{Et}_{3} \mathrm{~N}, \mathrm{LiOH} \cdot \mathrm{H}_{2} \mathrm{O}$, and $\mathrm{Me}_{4} \mathrm{NOH} \cdot 5 \mathrm{H}_{2} \mathrm{O}$. Crystalline products were obtained only with $\mathrm{X}^{-}=\mathrm{NO}_{3}{ }^{-}, \mathrm{MeCO}_{2}{ }^{-}$ and representative complexes are described in this work. In the case of $\mathrm{X}^{-}=\mathrm{Cl}^{-}$, powders with the empirical formulae (evidence from microanalyses) $\left\{\mathrm{LnCl}_{3}(\mathrm{mepaoH})_{3} \cdot n \mathrm{EtOH}\right\}$ $(n=1-2)$ were obtained from the reactions of hydrated lanthanoid chlorides and mepaoH in 1:3 reaction ratios in refluxing EtOH. We could not obtain single crystals for X-ray structural determination and so we did not pursue this chemistry further.

The 1:2 reactions between $\mathrm{Ln}\left(\mathrm{NO}_{3}\right)_{3} \cdot n \mathrm{H}_{2} \mathrm{O}(n=5$ or 6$)$ and mepaoH in $\mathrm{MeCN}$ gave almost colorless pale-colored (with the color of $\mathrm{Ln}^{\mathrm{III}}$ ) or colorless solutions from which crystals (in the case of $\mathrm{Nd}^{\mathrm{III}}$ and $\mathrm{Dy}{ }^{\mathrm{III}}$ ) or crystalline solids (in the case of Eu ${ }^{\mathrm{III}}, \mathrm{Gd}^{\mathrm{III}}$, and $\left.\mathrm{Tb}^{\mathrm{III}}\right)$ of $\left[\mathrm{Ln}_{2}\left(\mathrm{O}_{2} \mathrm{CMe}\right)_{4}\left(\mathrm{NO}_{3}\right)_{2}(\mathrm{mepaoH})_{2}\right](\mathrm{Ln}=\mathrm{Nd}, \mathbf{1} ; \mathrm{Ln}=\mathrm{Eu}, 2 ; \mathrm{Ln}=\mathrm{Gd}, 3 ; \mathrm{Ln}=\mathrm{Tb}$, $4 ; \mathrm{Ln}=\mathrm{Dy}, 5)$ were subsequently isolated in moderate yields $\left(30-40 \%\right.$ based on the $\mathrm{Ln}^{\text {III }}$ used). The stoichiometric 1:1 reactions gave again 1-5, albeit in lower yields ( 25\%). Given the absence of acetate ions from the reaction mixtures, the presence of acetato ligands in the products was surprising to us. The only source of coordinated $\mathrm{MeCO}_{2}{ }^{-}$groups in 1-5 could be the solvent used (MeCN), which contains $1-2 \%$ of $\mathrm{H}_{2} \mathrm{O}$. Assuming that the complexes are the only products from their respective reaction systems, and that the $\mathrm{H}_{2} \mathrm{O}$ responsible for the generation of acetates comes from the hydrated lanthanide(III) nitrates, the formation of the products can be summarized by the simplified Equation (1); $n=6$ for $\mathrm{Nd}(\mathrm{III}), \mathrm{Eu}(\mathrm{III}), \mathrm{Gd}(\mathrm{III}), \mathrm{Tb}(\mathrm{III})$, and 5 for $\mathrm{Dy}(\mathrm{III})$. As mentioned above, the $\mathrm{H}_{2} \mathrm{O}$ present in the solvent can also contribute to the formation of the $\mathrm{MeCO}_{2}{ }^{-}$ligands:

$$
\begin{aligned}
& 2 \mathrm{Ln}\left(\mathrm{NO}_{3}\right)_{3} \cdot n \mathrm{H}_{2} \mathrm{O}+2 \mathrm{mepaoH}+4 \mathrm{MeCN} \stackrel{\mathrm{MeCN}}{\rightarrow}\left[\operatorname{Ln}_{2}\left(\mathrm{O}_{2} \mathrm{CMe}\right)_{4}\left(\mathrm{NO}_{3}\right)_{2}(\mathrm{mepaoH})_{2}\right]+4 \mathrm{NH}_{4}\left(\mathrm{NO}_{3}\right) \\
& +(2 n-8) \mathrm{H}_{2} \mathrm{O}
\end{aligned}
$$

In accordance with our belief that Equation (1) represents the real chemistry of the reactions: (i) using more concentrated reaction solutions to increase the yields, the products were contaminated (IR and microanalyses evidences) by variable amounts of precipitated $\mathrm{NH}_{4}\left(\mathrm{NO}_{3}\right)$; the $\mathrm{H}_{2} \mathrm{O}$ present in the mixtures of the optimized reactions (Section 3) is enough to keep the $\mathrm{NH}_{4}\left(\mathrm{NO}_{3}\right)$ byproduct soluble, and (ii) employment of distilled $\mathrm{MeCN}$ as solvent leads to lower yields and serious contamination of the products by ammonium nitrate.

It is well known in organic chemistry that nitriles can be hydrolyzed to give either amides or carboxylic acids [48,49]. The initially produced hydroxylimine may tautomerize to an amide, which in turn generates a carboxylic acid upon further hydrolysis $[48,50]$. For $\mathrm{MeCN}$, the two hydrolysis steps are illustrated in Figure 2. Several metal ion-mediated processes for the hydration of nitriles with selective formation of metal-bound carboxamides are known [27,51-53], but most of the systems are not catalytic and only a few of them are able to hydrate $\mathrm{R}^{\prime}-\mathrm{C} \equiv \mathrm{N}$ under homogeneous catalytic conditions $[13,53]$, usually exhibiting a low activity [53]. The second step of the metal-ion mediated hydrolysis, i.e., conversion to carboxylic acids and ammonia, has been observed only in few cases involving $\mathrm{Pt}(\mathrm{IV})$, $\mathrm{Os}(\mathrm{IV})$, and $\mathrm{Nb}(\mathrm{V})$ systems [53]. To the best of our knowledge, the present work represents the second case in which an $\mathrm{Ln}(\mathrm{III})$-mediated hydrolysis of MeCN is experimentally observed. The first case involved the reactions of hydrated lanthanide(III) nitrates with 2-(4-carboxyphenyl)imidazo[4,5-f][1-10]phenanthroline (Hcpip) and 2-phenylimidazo [4,5$f][1-10]$ phenanthroline (pip) in $\mathrm{MeCN} / \mathrm{H}_{2} \mathrm{O}$ under solvothermal conditions $\left(\sim 190{ }^{\circ} \mathrm{C}\right)$, which gave the $1 \mathrm{D}$ coordination polymers $\left\{\left[\mathrm{Ln}_{2}\left(\mathrm{O}_{2} \mathrm{CMe}\right)_{4}(\mathrm{cpip})_{2}\right]\right\}_{\mathrm{n}}(\mathrm{Ln}=\mathrm{Sm}, \mathrm{Eu})$ and the dinuclear complexes $\left[\mathrm{Ln}_{2}\left(\mathrm{O}_{2} \mathrm{CMe}\right)_{6}(\text { pip })_{2}\right]$, respectively [54]. In the present case, the produced $\mathrm{MeCO}_{2} \mathrm{H}$ is neutralized by the also generated ammonia giving the acetato ligands 
and providing ammonium cations that provide charge balance for the released nitrate ions, Equation (1).

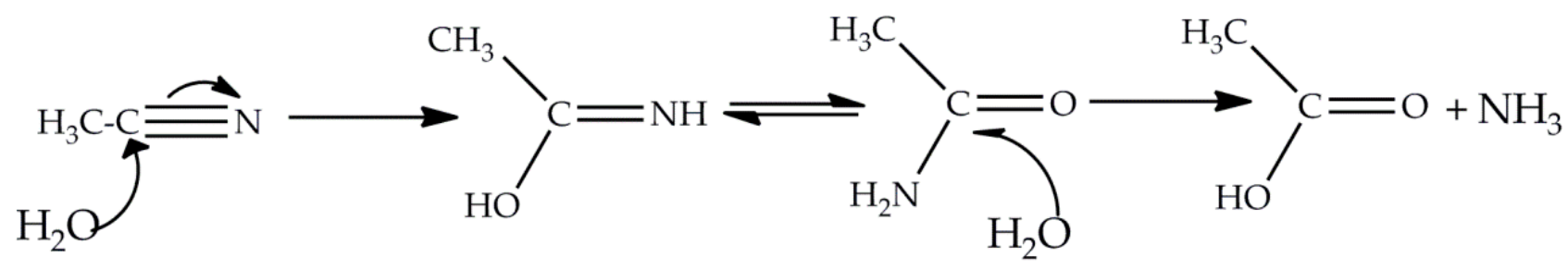

Figure 2. The hydrolysis of $\mathrm{MeCN}$ to generate $\mathrm{MeCO}_{2} \mathrm{H}$.

Having established the composition of 1-5, we wondered if we could obtain dinuclear $\mathrm{Ln}$ (III)/mepaoH complexes with six acetato ligands, i.e., without nitrato groups. Two procedures were investigated: (i) the reaction mixtures that lead to 1-5 were refluxed overnight, and (b) complexes 1-5 were treated with an excess (3-5 equivs per equiv of dinuclear complex) of an equimolar mixture of $\mathrm{MeCO}_{2} \mathrm{H}$ and $\mathrm{Et}_{3} \mathrm{~N}$ in $\mathrm{MeCN}$; in both cases, complexes $\left[\mathrm{Ln}_{2}\left(\mathrm{O}_{2} \mathrm{CMe}\right)_{4}\left(\mathrm{NO}_{3}\right)_{2}(\mathrm{mepaoH})_{2}\right]$ were again isolated, i.e., no reaction occurred. In a modification of the second route, the 1:6:6:2 $\mathrm{Ln}\left(\mathrm{NO}_{3}\right)_{3} \cdot n \mathrm{H}_{2} \mathrm{O} / \mathrm{MeCO}_{2} \mathrm{H} / \mathrm{Et}_{3} \mathrm{~N} /$ mepaoH reaction mixtures in MeCN gave again complexes 1-5 in moderate yields (25-35\% based on the $\mathrm{Ln}^{\mathrm{III}}$ available), Equation (2). This is strong evidence that the mixed acetato/nitrato complexes are the thermodynamically preferred products from the $\mathrm{Ln}^{\mathrm{III}} / \mathrm{NO}_{3}{ }^{-} / \mathrm{MeCO}_{2}{ }^{-} / \mathrm{mepaoH}$ reaction systems in $\mathrm{MeCN}$ :

$$
\begin{gathered}
2 \mathrm{Ln}\left(\mathrm{NO}_{3}\right)_{3} \cdot n \mathrm{H}_{2} \mathrm{O}+2 \text { mepaoH }+4 \mathrm{MeCO}_{2} \mathrm{H}+4 \mathrm{Et}_{3} \mathrm{~N} \stackrel{\mathrm{MeCN}}{\rightarrow}\left[\operatorname{Ln}_{2}\left(\mathrm{O}_{2} \mathrm{CMe}\right)_{4}\left(\mathrm{NO}_{3}\right)_{2}(\mathrm{mepaoH})_{2}\right] \\
+4\left(\mathrm{Et}_{3} \mathrm{NH}\right)\left(\mathrm{NO}_{3}\right)+2 n \mathrm{H}_{2} \mathrm{O}
\end{gathered}
$$

The obvious route to prepare all-acetato dinuclear $\mathrm{Ln}(\mathrm{III}) / \mathrm{mepaoH}$ complexes was to avoid the presence of $\mathrm{NO}_{3}{ }^{-}$ions in the reaction systems. This was examined in the case of Dy(III). Thus, the refluxing 1:1 or 1:2 reactions between $\mathrm{Dy}\left(\mathrm{O}_{2} \mathrm{CMe}\right)_{3} \cdot 4 \mathrm{H}_{2} \mathrm{O}$ and mepaoH in a solvent mixture of $\mathrm{MeOH} / \mathrm{MeCN}(1: 2 v / v)$ led to a slurry, the filtration of which gave an almost colorless solution from which colorless crystals of $\left[\mathrm{Dy}_{2}\left(\mathrm{O}_{2} \mathrm{CMe}\right)_{6}(\mathrm{mepaoH})_{2}\right](6)$ were subsequently isolated in good yield (50-60\% based on $\mathrm{Dy}{ }^{\mathrm{III}}$ ), Equation (3). $\mathrm{MeOH}$ was necessary to keep an amount of $\mathrm{Dy}\left(\mathrm{O}_{2} \mathrm{CMe}\right)_{3} \cdot 4 \mathrm{H}_{2} \mathrm{O}$ (insoluble in $\mathrm{MeCN}$ ) soluble in order to react with the ligand; the reaction in $\mathrm{MeOH}$ and subsequent precipitation with $\mathrm{Et}_{2} \mathrm{O}$ gave a powder, most probably (IR evidence) a mixture of 6 and $\mathrm{Dy}\left(\mathrm{O}_{2} \mathrm{CMe}\right)_{3} \cdot 4 \mathrm{H}_{2} \mathrm{O}$. Treatment of 6 with 2-2.5 equivs of $\mathrm{HNO}_{3}$ (from a 2N solution) in MeCN gave complex 5, Equation (4), emphasizing again the thermodynamic stability of the mixed acetato/nitrato complexes. Excess of $2 \mathrm{~N} \mathrm{HNO}_{3}$ leads to the decomposition of the product:

$$
\begin{gathered}
2 \mathrm{Dy}\left(\mathrm{O}_{2} \mathrm{CMe}\right)_{3} \cdot 4 \mathrm{H}_{2} \mathrm{O}+2 \text { mepaoH } \stackrel{\mathrm{MeOH} / \mathrm{MeCN}}{\rightarrow}\left[\mathrm{Dy}_{2}\left(\mathrm{O}_{2} \mathrm{CMe}\right)_{6}(\text { mepaoH })_{2}\right]+8 \mathrm{H}_{2} \mathrm{O} \\
{\left[\mathrm{Dy}_{2}\left(\mathrm{O}_{2} \mathrm{CMe}\right)_{6}(\mathrm{mepaoH})_{2}\right]+8 \mathrm{HNO}_{3} \stackrel{\mathrm{MeCN}}{\rightarrow}\left[\mathrm{Dy}_{2}\left(\mathrm{O}_{2} \mathrm{CMe}_{4}\left(\mathrm{NO}_{3}\right)_{2}(\text { mepaoH })_{2}\right]+2 \mathrm{MeCO}_{2} \mathrm{H}\right.}
\end{gathered}
$$

\subsection{Description of Structures}

The structures of 1, 5, and 6 were determined by single-crystal X-ray crystallography. Crystallographic data are listed in the Supplementary Table S1. Various structural plots are shown in Figures 3-7 and Supplementary Figures S1-S3. Selected interatomic distances and bond angles are given in Tables 1 and 2. CShM values for the potential coordination polyhedra of the $\mathrm{Ln}^{\mathrm{III}}$ centers in 1, 5, and $\mathbf{6}$ are summarized in Table S2, while H-bonding interactions for the three structures are listed in Tables S3 and S4. 


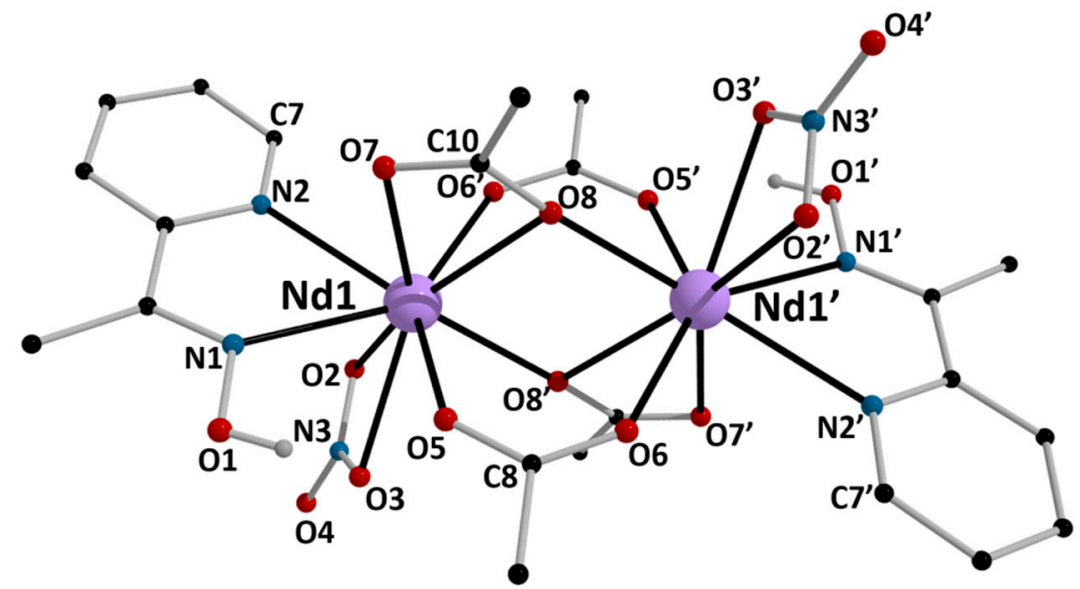

Figure 3. Partially labeled plot of the structure of the dinuclear molecule $\left[\mathrm{Nd}_{2}\left(\mathrm{O}_{2} \mathrm{CMe}\right)_{4}\left(\mathrm{NO}_{3}\right)_{2}(\mathrm{mepaoH})_{2}\right]$ that is present in the crystal of 1 . Symmetry operation: $(')=-x+2,-y+1,-z+2$.

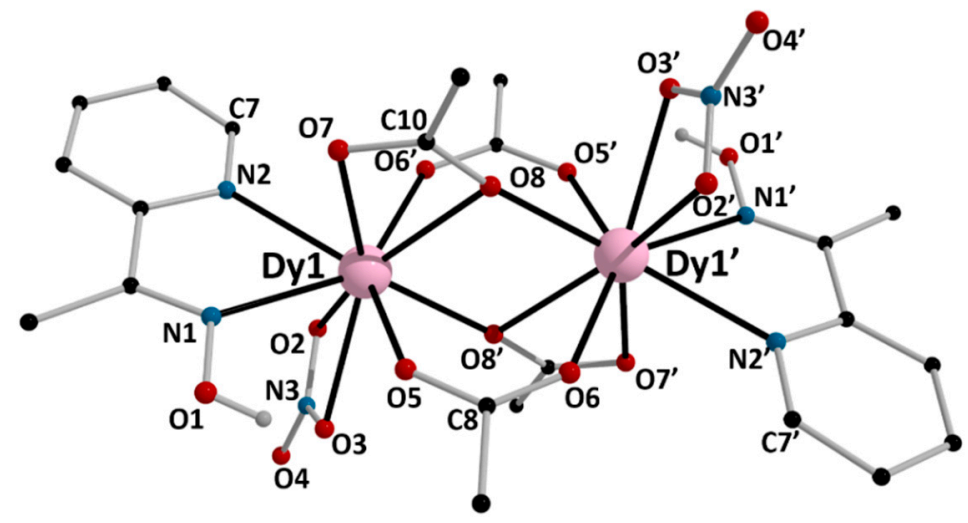

Figure 4. Partially labeled plot of the structure of the dinuclear molecule $\left[\mathrm{Dy}_{2}\left(\mathrm{O}_{2} \mathrm{CMe}\right)_{4}\left(\mathrm{NO}_{3}\right)_{2}(\mathrm{mepaoH})_{2}\right]$ that is present in the crystal of 5 . Symmetry operation: $\left({ }^{\prime}\right)=-x+2,-y+1,-z+2$.

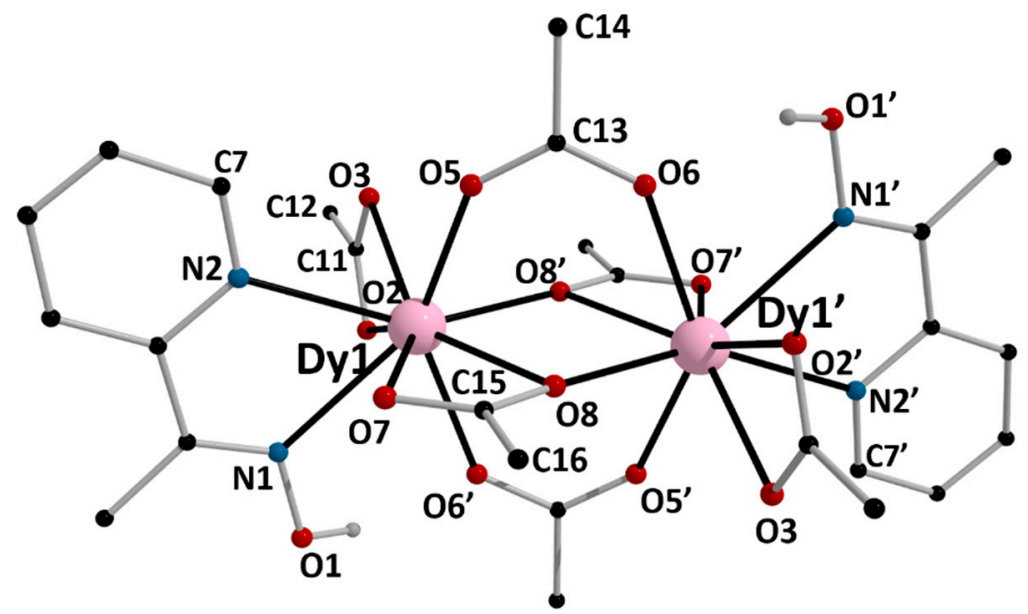

Figure 5. Partially labeled plot of the structure of the dinuclear molecule $\left[\mathrm{Dy}_{2}\left(\mathrm{O}_{2} \mathrm{CMe}\right)_{6}(\mathrm{mepaoH})_{2}\right]$ that is present in the crystal of 6 . Symmetry operation: $\left({ }^{\prime}\right)=-x,-y,-z$. 

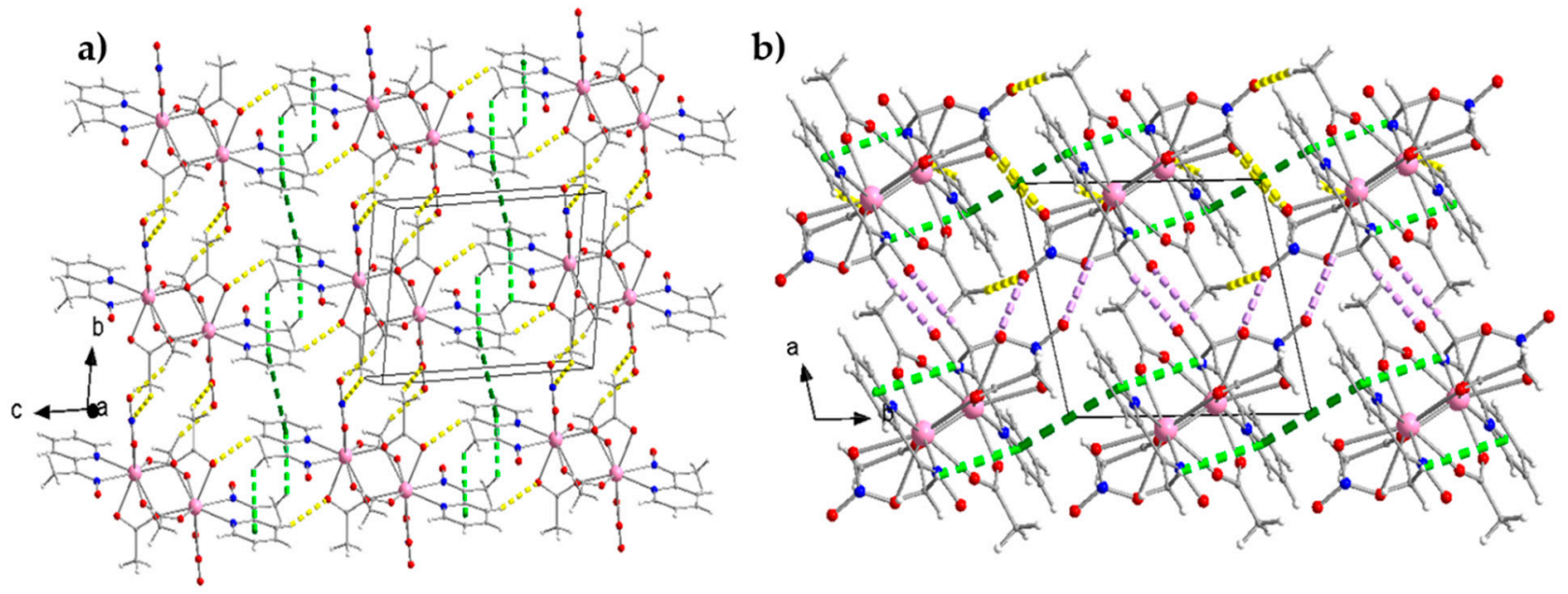

Figure 6. (a) 2D arrangement of the isomorphous complexes 1 and 5 parallel to the (100) plane. Thick dashed yellow lines indicate the $\mathrm{C} 4-\mathrm{H}(\mathrm{C} 4) \cdots \mathrm{O} 7(2.49 \AA), \mathrm{C} 9-\mathrm{H}_{\mathrm{B}}\left(\mathrm{C}_{\mathrm{g}}\right) \cdots \mathrm{O} 4(2.43 \AA)$ and $\mathrm{C} 11-\mathrm{H}_{\mathrm{B}}(\mathrm{C} 11) \cdots \mathrm{O} 2(2.60 \AA) \mathrm{H}$ bonds, where C4 is an aromatic carbon atom of the mepaoH ligand and C9, C11 are the methyl carbon atoms of the crystallographically independent acetato groups. Thick dashed light green and dark green lines represent the $\mathrm{C}-\mathrm{H} \cdots \pi$ and $\pi \cdots \pi$ interactions, respectively, described in the text; (b) stacking of layers parallel to the $a$ crystallographic axis for $\mathbf{1}$ and $\mathbf{5}$. Thick dashed violet lines represent the $\mathrm{C} 1-\mathrm{H}_{\mathrm{A}}(\mathrm{C} 1) \cdots \mathrm{O} 1(2.52 \AA)$ and $\mathrm{C} 1-\mathrm{H}_{\mathrm{B}}(\mathrm{C} 1) \cdots \mathrm{O} 4(2.59 \AA) \mathrm{H}$ bonds, where $\mathrm{C} 1$ is the methyl carbon atom of the mepaoH ligand. All the distance and angle parameters for the $\mathrm{H}$ bonds, as well as the symmetry operations are listed in Table S3.
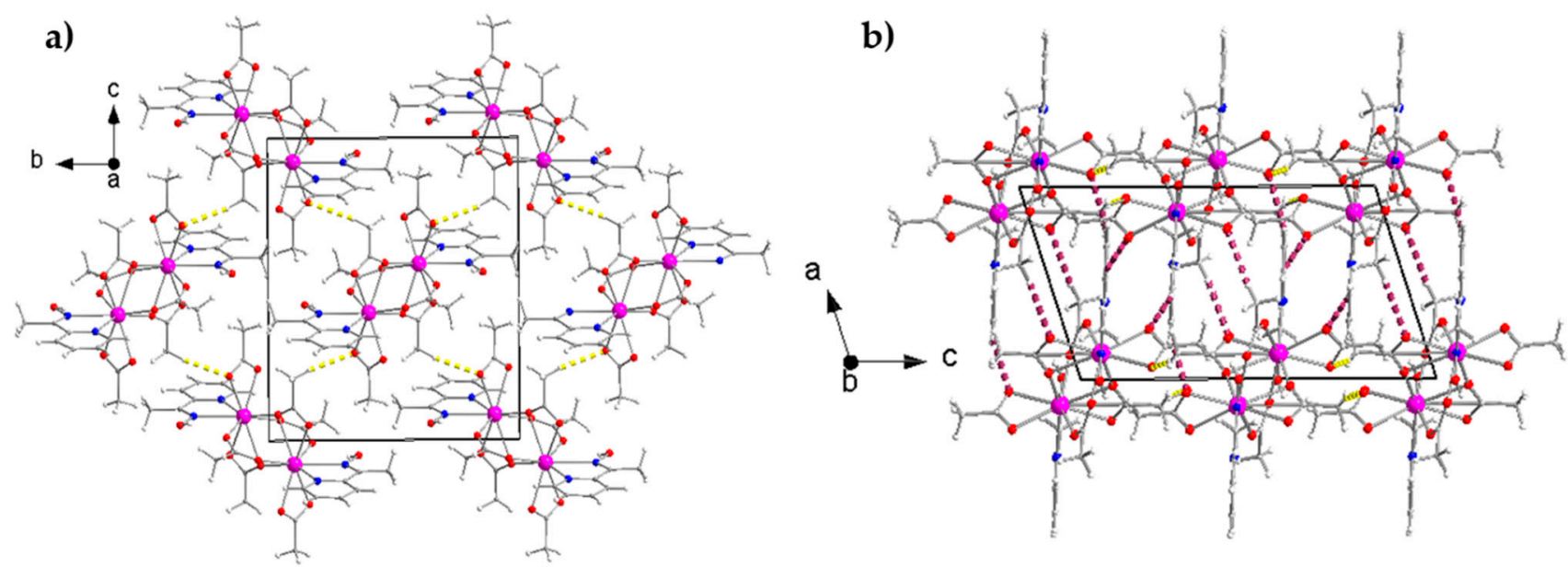

Figure 7. Intermolecular interactions in the crystal structure of complex 6. (a) 2D arrangement of the dinuclear molecules parallel to the (100) plane. Thick dashed yellow lines indicate the $\mathrm{C} 16-\mathrm{Hc}(\mathrm{C} 16) \cdots \mathrm{O} 2(2.46 \AA) \mathrm{H}$ bond, where C16 is the methyl carbon atom of the crystallographically unique $\eta^{1}: \eta^{2}: \mu_{2}(2.12)$ acetato group; (b) stacking of layers parallel to the $\alpha$

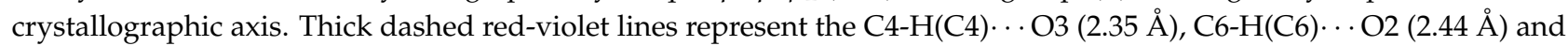
C14- $\mathrm{H}_{\mathrm{C}}(\mathrm{C} 14) \cdots \mathrm{O} 7(2.58 \AA) \mathrm{H}$ bonds; $\mathrm{C} 4$ and C6 are aromatic carbon atoms of the mepaoH ligand. The distances and angles for the $\mathrm{H}$ bonds, as well as the symmetry operations are listed in Table S4.

Table 1. Selected interatomic distances $(\AA)$ and angles $\left(^{\circ}\right)$ for complexes $\mathbf{1}$ and $5^{\mathrm{a}}$.

\begin{tabular}{ccc}
\hline \multicolumn{3}{c}{ Interatomic Distances $(\AA)$} \\
\hline Ln1 $\cdots$ Ln1 ${ }^{\prime}$ & $1(\mathrm{Ln}=\mathrm{Nd})$ & $5(\mathrm{Ln}=\mathrm{Dy})$ \\
Ln1-O2 & $3.877(1)$ & $3.795(1)$ \\
Ln1-O3 & $2.555(6)$ & $2.453(9)$ \\
Ln1-O5 & $2.577(5)$ & $2.499(10)$ \\
& $2.426(5)$ & $2.343(7)$ \\
\hline
\end{tabular}


Table 1. Cont.

\begin{tabular}{ccc}
\hline & Interatomic Distances (̊̊) \\
\hline Ln1-O6' & $2.404(4)$ & $2.312(8)$ \\
Ln1-O7 & $2.503(5)$ & $2.421(8)$ \\
Ln1-O8 & $2.578(4)$ & $2.522(8)$ \\
Ln1-O8' & $2.385(5)$ & $2.281(7)$ \\
Ln1-N1 & $2.582(6)$ & $2.510(11)$ \\
Ln1-N2 & $2.612(5)$ & $2.535(9)$ \\
N3-O2 & $1.273(8)$ & $1.289(15)$ \\
N3-O3 & $1.243(8)$ & $1.266(13)$ \\
N3-O4 & $1.228(8)$ & $1.230(13)$ \\
C8-O5 & $1.265(8)$ & $1.274(13)$ \\
C8-O6 & $1.251(8)$ & $1.253(14)$ \\
C10-O7 & $1.227(8)$ & $1.236(13)$ \\
C10-O8 & $1.289(9)$ & $1.293(12)$ \\
N1-O1 & $1.390(7)$ & $1.386(13)$ \\
\hline N1-Ln1-N2 & \\
O2-Ln1-O3 & Interatomic Angles $\left.\mathbf{(}^{\mathbf{0}}\right)$ & $62.9(3)$ \\
O7-Ln1-O8 & $61.1(2)$ & $52.4(3)$ \\
N2-Ln1-O8' & $49.8(2)$ & $52.6(2)$ \\
O6'-Ln1-O7 & $50.7(2)$ & $147.1(3)$ \\
O2-Ln1-O5 & $148.7(2)$ & $90.2(3)$ \\
O2-Ln1-O8 & $91.8(2)$ & $123.4(3)$ \\
Ln1-O8-Ln1' & $120.4(2)$ & $150.1(3)$ \\
\hline
\end{tabular}

a Symmetry code: $\left(^{\prime}\right)=-x+2,-y+1,-z+2$.

Table 2. Selected interatomic distances $(\AA)$ and angles $\left(^{\circ}\right)$ for complex $6^{\mathrm{a}}$.

\begin{tabular}{|c|c|c|c|}
\hline \multicolumn{2}{|c|}{ Interatomic Distances (̊̊) } & \multicolumn{2}{|c|}{ Interatomic Angles $\left(^{\circ}\right)$} \\
\hline Dy $1 \cdots$ Dy $^{\prime}$ & $3.859(1)$ & N1-Dy1-N2 & $61.9(2)$ \\
\hline Dy1-O2 & $2.413(5)$ & O2-Dy1-O3 & $53.7(2)$ \\
\hline Dy1-O3 & $2.421(5)$ & O7-Dy1-O8 & $52.0(2)$ \\
\hline Dy1-O5 & $2.361(5)$ & O2-Dy1-O8' & $83.8(2)$ \\
\hline Dy1-O6' & $2.382(5)$ & O3-Dy1-O6' & $130.6(2)$ \\
\hline Dy1-O7 & $2.414(5)$ & O5-Dy1-O7 & $81.4(2)$ \\
\hline Dy1-O8 & $2.561(5)$ & O3-Dy1-O8 & $143.0(2)$ \\
\hline Dy1-O8' & $2.296(5)$ & O3-Dy1-O8' & $81.4(2)$ \\
\hline Dy1-N1 & $2.593(8)$ & O2-Dy1-O8 & $147.0(2)$ \\
\hline Dy1-N2 & $2.525(7)$ & O2-Dy1-O5 & $128.4(2)$ \\
\hline $\mathrm{C} 11-\mathrm{O} 2$ & $1.259(9)$ & N1-Dy1-O5 & $142.5(2)$ \\
\hline C11-O3 & $1.254(9)$ & N1-Dy1-O8 & $109.8(2)$ \\
\hline $\mathrm{C} 13-\mathrm{O} 5$ & $1.242(9)$ & N2-Dy1-O3 & $72.9(2)$ \\
\hline C13-O6 & $1.279(9)$ & N2-Dy1-O5 & $84.6(2)$ \\
\hline C15-O7 & $1.252(8)$ & N2-Dy1-O8 & $119.9(2)$ \\
\hline $\mathrm{C} 15-\mathrm{O} 8$ & $1.262(8)$ & Dy1-O8-Dy1' & $105.1(2)$ \\
\hline N1-O1 & $1.395(9)$ & & \\
\hline
\end{tabular}

a Symmetry code: $\left(^{*}\right)=-x,-y,-z$.

Complexes $\mathbf{1}$ and $\mathbf{5}$ crystallize in the triclinic space group $P \overline{\mathbf{1}}$ and are isomorphous; thus, a general description will be given $(\mathrm{Ln}=\mathrm{Nd}$, Dy). The structures consist of dinuclear molecules $\left[\mathrm{Ln}_{2}\left(\mathrm{O}_{2} \mathrm{CMe}\right)_{4}\left(\mathrm{NO}_{3}\right)_{2}(\mathrm{mepaoH})_{2}\right]$. There is a crystallographically imposed inversion center at the midpoint of the $\mathrm{Ln} \cdots \mathrm{Ln}^{\prime}$ vector. The $\mathrm{Ln}{ }^{\mathrm{III}}$ atoms are each chelated by a $N, N^{\prime}$-bidentate mepaoH ligand ( $\eta^{2}$ or 1.011 using Harris notation [55]) and an almost symmetrical bidentate nitrato group $\left(\eta^{2}\right.$ or 1.110). The metal centers are bridged by two pairs of acetato ligands. One of them consists of symmetrical syn, syn $\eta^{1}: \eta^{1}: \mu_{2}$ (or 2.11) groups, the Ln1-O5 and Ln1-O6' bond lengths being 2.426(5) and 2.404(4) $\AA$, respectively, for 1, and 2.343(7) and 2.312(8) $\AA$, for 5, respectively. The second pair of bridging acetato groups 
are best described as chelating-bridging $\left(\eta^{1}: \eta^{2}: \mu_{2}\right.$ or 2.12), since, in addition to the two typical Ln1-O bonds [Nd1-O7 = 2.503(5) $\AA$, Nd1-O8 ${ }^{\prime}=2.385(5) \AA$ and Dy1-O7 $=2.421(8) \AA$, $\left.\mathrm{Dy}_{1-\mathrm{O}^{\prime}}=2.281(7) \AA\right]$, there is now a weaker Ln1-O bond $[\mathrm{Nd} 1-\mathrm{O} 8=2.578(4) \AA$ and Dy1-O8 $=2.522(8) \AA]$. Considering only the monoatomic O-bridges $\left(\mathrm{O} 8, \mathrm{O}^{\prime}\right)$, the strictly planar (by symmetry) core of the complexes is $\left\{\mathrm{Ln}^{\mathrm{III}} 2\left(\mu_{2}-\mathrm{OR}^{\prime}\right)_{2}\right\}^{4+}$, where $\mathrm{RO}^{-}=\mathrm{MeCO}_{2}{ }^{-}$.

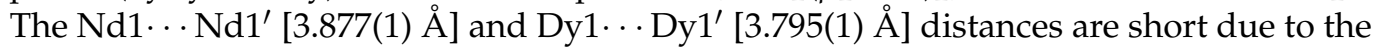
quadruplicate bridge. The Ln1-O8/O $8^{\prime}-\mathrm{Ln}^{\prime}$ angles are 102.7(2) and $104.3(3)^{\circ}$ for $\mathbf{1}$ and 5, respectively. The nitrato $\mathrm{N}-\mathrm{O}$ bond lengths involving the "free" oxygen atom are slightly shorter to those involving the coordinated oxygen atoms; for example, the N3-O4 bond length in 5 is 1.230(13) $\AA$, while the N3-O2 and N3-O3 bond distances are 1.289(15) and $1.266(13) \AA$, respectively. The presence of monoatomic oxygen bridges in the 2.12 acetato ligands results in a significant difference between the lengths of the two carboxylate $\mathrm{C}-\mathrm{O}$ bonds, the C10-O8 distance [1.289(9) $\AA$ for $\mathbf{1}$ and 1.293(12) $\AA$ for 5 being longer than the C10-O7 distance [1.227(8) $\AA$ for $\mathbf{1}$ and 1.236(13) $\AA$ for 5]. For a given bond, the Ln-O/N bond lengths follow the $\mathrm{Nd}>$ Dy order (Table 1) due to lanthanide contraction; this trend is also observed for the $\mathrm{Ln}^{\mathrm{III}} \ldots \mathrm{Ln}^{\mathrm{III}}$ distances. The $\mathrm{Ln}-\mathrm{O} / \mathrm{N}$ bond lengths in $\mathbf{1}$ and $\mathbf{5}$ are typical for 9-coordinate $\mathrm{Nd}$ (III) $[33,56,57]$ and Dy(III) $[35,38,41,54,58-62]$. The Ln1/Ln1' coordination geometry was evaluated using the program SHAPE $[61,63]$ and is best described as muffin-type (Figure S1, Table S2); an alternative description of the polyhedron could be that of a spherical-capped square antiprism.

There are two crystallographically independent $\mathrm{H}$ bonds within the dinuclear molecules (intramolecular H bonds, Figure S2 and Table S3). The donors are the oxime oxygen atoms $\left(\mathrm{O} 1 / \mathrm{O}^{\prime}\right)$ and the aromatic carbon atoms $\mathrm{C} 7 / \mathrm{C7}^{\prime}$, and the acceptors are the coordinated acetato oxygen atoms $\mathrm{O} 5 / \mathrm{O}^{\prime}$ and $\mathrm{O}^{\prime} / \mathrm{O} 6$, respectively. Given the rather small donor$\mathrm{H} \cdot \cdots$ acceptors angles, these bonds can be considered as weak.

Complex 6 crystallizes in the monoclinic space group $P 2_{1} / c$. Although its composition is different compared with that of $\mathbf{5}$ (and $\mathbf{1}$ ), the molecular structures are similar. The only significant difference is the presence of the two chelating acetato groups $\left(\eta^{2}\right.$ or 1.11) in 6 instead of the two chelating nitrato groups $\left(\eta^{2}\right.$ or 1.110) in 5. Again, the two Dy ${ }^{\mathrm{III}}$ centers are linked by four $\mathrm{MeCO}_{2}{ }^{-}$ligands. Two of them bridge in the classical syn, syn $\eta^{1}: \eta^{1}: \mu_{2}$ (or 2.11) fashion, and the other two bridge in the less common $\eta^{1}: \eta^{2}: \mu_{2}$ (2.12) mode; the latter have an oxygen atom $\left(\mathrm{O} 7, \mathrm{O}^{\prime}\right)$ bound terminally to one metal ion, and the oxygen atom $\left(\mathrm{O} 8, \mathrm{O}^{\prime}\right)$ bound in a $\mu_{2}$ manner to both $\mathrm{Dy} \mathrm{III}^{\mathrm{III}}$ atoms, forming a monoatomic bridge. One chelating 1.011 mepaoH molecule and one chelating (1.11) $\mathrm{MeCO}_{2}{ }^{-}$ion complete 9-coordination at each metal center. Due to the inversion center, the Dy1O8Dy1 ${ }^{\prime} \mathrm{O} 8^{\prime}$ core is perfectly planar. The coordination polyhedron of Dy1/Dy1' is best described as muffin (Figure S1, Table S2). The interatomic distances and bond angles in $\mathbf{6}$ and $\mathbf{5}$ are similar; a notable difference is that the Dy- $\mathrm{N}_{\text {oxime }}$ bond length [2.593(8) $\AA$ ] is larger than that of the Dy- $\mathrm{N}_{\text {pyridyl }}$ bond length [2.525(7) $\AA$ ] in 6, while the opposite trend [2.510(11) vs. 2.535(9) $\AA$, respectively] is observed in $\mathbf{5}$.

There are two crystallographically independent, weak intramolecular $\mathrm{H}$ bonds in

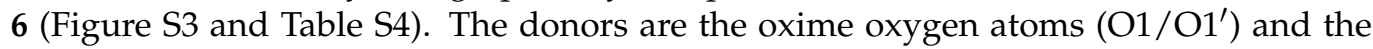
aromatic carbon atoms $\mathrm{C} 7 / \mathrm{C}^{\prime}$, and the acceptors are the coordinated acetato oxygen atoms $\mathrm{O}^{\prime} / \mathrm{O} 6$ and $\mathrm{O} 5 / \mathrm{O}^{\prime}$, respectively.

At the supramolecular level, the crystal structures of the isomorphous complexes $\mathbf{1}$ and 5 are stabilized by intermolecular $\mathrm{H}$ bonds (Table S3), $\pi-\pi$ overlaps and $\mathrm{C}-\mathrm{H} \cdots \pi$ interactions. The distance between the centrosymmetrically-related pyridyl rings $\mathrm{N} 2 \mathrm{C} 3 \mathrm{C} 4 \mathrm{C} 5 \mathrm{C} 6 \mathrm{C} 7$ and $\mathrm{N} 2{ }^{*} \mathrm{C} 3{ }^{*} \mathrm{C} 4{ }^{*} \mathrm{C} 5{ }^{*} \mathrm{C} 6{ }^{*} \mathrm{C} 7^{*}\left[\left({ }^{*}\right)=-x+2,-y,-z+1\right]$ is 3.74(3) $\AA$ for $\mathbf{1}$ and 3.73(5) $\AA$ for 5. The $\mathrm{C}-\mathrm{H} \cdots \pi$ interactions are evaluated using the $\mathrm{Hc}(\mathrm{C} 1) \cdots \mathrm{C}_{\mathrm{g}} 1^{* *}$ distance, which is 3.068(1) $\AA$ for 1 and 2.910(1) $\AA$ for $\left.5\left[{ }^{(* *}\right)==-x+2,-y+1,-z+1\right] ; C_{g} 1$ is the centroid of the pyridyl ring of mepaoH, and $\mathrm{Hc}(\mathrm{C} 1)$ is one of the methyl hydrogen atoms of mepaoH. Thus, layers of molecules are formed parallel to the (100) plane (Figure 6a). The layers interact through $\mathrm{H}$ bonds and are stacked along the $a$ crystallographic axis, thus building the 3D architectures (Figure 6b). 
The crystal structure of $\mathbf{6}$ is built through $\mathrm{H}$ bonds (Table S4). The dinuclear molecules form layers parallel to the (100) plane (Figure 7a), which interact further to create the 3D architecture of the structure (Figure $7 \mathrm{~b}$ ).

Complexes 1, 5, and $\mathbf{6}$ are members of a rather large family of dinuclear complexes containing the $\left\{\operatorname{Ln}_{2}\left(\eta^{1}: \eta^{1}: \mu_{2}-\mathrm{O}_{2} \mathrm{CMe}\right)_{2}\left(\eta^{1}: \eta^{2}: \mu_{2}-\mathrm{O}_{2} \mathrm{CMe}\right)_{2}\right\}^{2+}$ unit $[39,54,56-60,64-66] ;$ (only representative references are given), most of which $[54,58,60,64,65]$ contain an extra chelating acetato group per $\mathrm{Ln}{ }^{\mathrm{III}}$ center; complexes containing a chelating nitrato group per $\mathrm{Ln}^{\mathrm{III}}$ atom, i.e., the unit $\left\{\mathrm{Ln}_{2}\left(\eta^{1}: \eta^{1}: \mu_{2}-\mathrm{O}_{2} \mathrm{CMe}\right)_{2}\left(\eta^{1}: \eta^{2}: \mu_{2}-\mathrm{O}_{2} \mathrm{CMe}\right)_{2}-\left(\eta^{2}-\mathrm{OONO}\right)\right\}$, are few $[39,56,59,66]$.

\subsection{Characterization of Selected Complexes}

In the solid-state (KBr) IR spectra of $\mathbf{1 - 6}$, the presence of a medium-intensity band at $\sim 3250 \mathrm{~cm}^{-1}$ is assigned to the $v(\mathrm{OH})$ vibration of the mepaoH ligand $[18,21]$; the broadness and the relatively low wavenumber of the band are both indicative of H-bonding interactions established by crystallography (vide supra). The medium-intensity band at $1116 \mathrm{~cm}^{-1}$ in the spectrum of free mepaoH has been assigned to the $v(\mathrm{OH})_{\text {oxime }}$ mode [21]; this band has been shifted to lower wavenumber $\left(\sim 1090 \mathrm{~cm}^{-1}\right)$ in the spectra of the six complexes due to coordination of the oxime nitrogen [21]. The in-plane pyridyl deformation of free mepaoH at $632 \mathrm{~cm}^{-1}$ shifts upwards in the spectra of the complexes $\left(\sim 685 \mathrm{~cm}^{-1}\right)$ confirming the involvement of the ring $\mathrm{N}$-atom in coordination [18,24,32]. The spectra of $\mathbf{1}-\mathbf{5}$ are almost identical supporting similar structures of the complexes $\left[\mathrm{Ln}_{2}\left(\mathrm{O}_{2} \mathrm{CMe}\right)_{4}\left(\mathrm{NO}_{3}\right)_{2}(\mathrm{mepaoH})_{2}\right]$ $(\mathrm{Ln}=\mathrm{Nd}, \mathrm{Eu}, \mathrm{Gd}, \mathrm{Tb}, \mathrm{Dy})$. Many bands appear in the $1370-1630 \mathrm{~cm}^{-1}$ region in the IR spectra of 1-6. Contributions from the $\delta(\mathrm{OH})_{\text {oxime, }} v(\mathrm{C}=\mathrm{N})_{\text {oxime, }}, v_{\text {as }}\left(\mathrm{CO}_{2}\right), v_{\mathrm{s}}\left(\mathrm{CO}_{2}\right)$, aromatic ring stretching vibrations and nitrato stretching modes (for 1-5) would be expected in this region, rendering exact assignments and discussion of the coordination shifts rather impossible. The bands at 1500, 1295, and $\sim 96 \mathrm{~cm}^{-1}$ in $\mathbf{1 - 5}$ are assigned to the $v_{1}\left(\mathrm{~A}_{1}\right)\left[v(\mathrm{~N}=\mathrm{O}], v_{5}\left(\mathrm{~B}_{2}\right)\left[v_{\text {as }}\left(\mathrm{NO}_{2}\right)\right]\right.$ and $v_{2}\left(\mathrm{~A}_{1}\right)\left[v_{\mathrm{s}}\left(\mathrm{NO}_{2}\right)\right]$ vibrational modes, respectively, of the nitrato group [67]; the separation of the two highest-wavenumber stretching bands is large $\left(\sim 200 \mathrm{~cm}^{-1}\right)$ and typical for bidentate chelating $\left(C_{2 \mathrm{v}}\right)$ nitrato groups [67]. These three bands do not appear in the spectrum of the nitrate-free compound $\mathbf{6}$.

The luminescence of $\mathrm{Ln}^{\mathrm{III}}$ ions results from electronic transitions within the partially filled $4 \mathrm{f}^{\mathrm{n}}$ orbitals. Due to the intrinsically low probability of such electronic $4 \mathrm{f}-4 \mathrm{f}$ transitions, the photon absorption cross section and the emission brightness are small. A common approach to overcome this disadvantage is to take advantage of a sensitizing entity (usually an organic ligand) that can effectively harvest the excitation energy and transfer it to the $\mathrm{Ln}^{\mathrm{III}}$ ion. An ideal organic ligand for this purpose should: (i) feature a large photon absorption cross section; and (ii) exhibit an energy level scheme that allows for an effective transfer of the absorbed energy to the $\mathrm{Ln}^{\mathrm{III}}$ center [68-71]. Since $\mathrm{Eu}(\mathrm{III})$ and $\mathrm{Tb}(\mathrm{III})$ complexes often emit light in the visible region of the electromagnetic spectrum, we investigated the photoluminescence properties of complexes 2 and 4 (Figures 8 and 9, respectively).

The free mepaoH ligand emits with a maximum at $\sim 540 \mathrm{~nm}$, upon maximum excitation at $397 \mathrm{~nm}$. Upon the same maximum excitation $(397 \mathrm{~nm})$, the solid complex $\left[\mathrm{Eu}_{2}\left(\mathrm{O}_{2} \mathrm{CMe}\right)_{4}\left(\mathrm{NO}_{3}\right)_{2}(\mathrm{mepaoH})_{2}\right]$ (2) displays emission peaks at 593, 618, 653, and $695 \mathrm{~nm}$ due to $\mathrm{Eu}^{\mathrm{III}}[41,68,69]$. These peaks are assigned to the characteristic ${ }^{5} D_{0} \rightarrow{ }^{7} F_{\mathrm{j}}(\mathrm{j}=0-4)$ transitions of this metal ion. Specific assignments $[41,43]$ are as follows: ${ }^{5} D_{0} \rightarrow{ }^{7} F_{0,1}(593 \mathrm{~nm})$; ${ }^{5} D_{0} \rightarrow{ }^{7} F_{2}(618 \mathrm{~nm}) ;{ }^{5} D_{0} \rightarrow{ }^{7} F_{3}(653 \mathrm{~nm}) ;{ }^{5} D_{0} \rightarrow{ }^{7} F_{4}(695 \mathrm{~nm})$. The dominant peak is due to the hypersensitive ${ }^{5} D_{0} \rightarrow{ }^{7} F_{2}$ transition. The higher intensity of this transition compared with that of the magnetic-dipole allowing ${ }^{5} D_{0} \rightarrow{ }^{7} F_{1}$ transition indicates that this complex has a structure with no imposed symmetry at Eu ${ }^{\mathrm{III}}$ (the molecules of 2, which are proposed to be isostructural with those of the crystallographically characterized $\mathbf{1}$ and $\mathbf{5}$, have an inversion center at the midpoint of the $\mathrm{Ln}^{\mathrm{III}}$... $\mathrm{Ln}^{\mathrm{III}}$ vector). Generally, complexes with a centrosymmetric coordination sphere of $\mathrm{Eu}^{\mathrm{III}}$ (which is not the case in 2) have a $\left({ }^{5} D_{0} \rightarrow{ }^{7} F_{2}\right) /\left({ }^{5} D_{0} \rightarrow{ }^{7} F_{1}\right)$ intensity ratio lower than 0.7 [41]. The lifetime of the excited state of $\mathrm{Eu}(\mathrm{III})$ was found to be $0.68 \mathrm{~ms}$, a value typical for $\mathrm{Ln}(\mathrm{III})$ complexes $[43,71]$. 


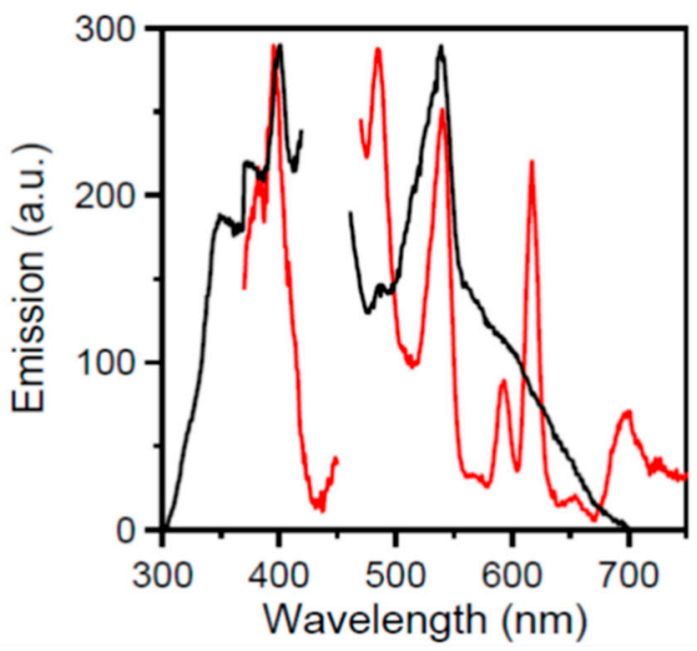

Figure 8. Solid-state, room-temperature excitation (left) and emission (right) spectra of mepaoH (black curves) and complex 2 (red curves). The emission spectra were detected at $397 \mathrm{~nm}$ for both compounds. The excitation spectra were detected with maximum emission at $545 \mathrm{~nm}$ for mepaoH and $618 \mathrm{~nm}$ for 2 .

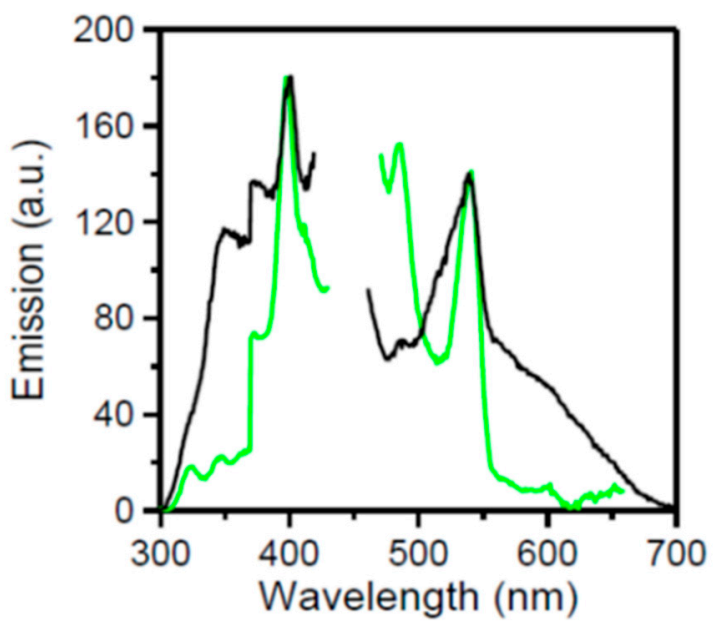

Figure 9. Solid-state, room-temperature excitation (left, emission, at 545) and emission (right, excitation at $397 \mathrm{~nm}$ ) of mepaoH (black curves) and complex 4 (green curves).

The emission peaks at $\sim 545$ and $\sim 490 \mathrm{~nm}$ arise from the coordinated mepaoH ligand, since the free ligand (black curve in Figure 8) emits in this area with maxima at approximately these wavelengths (the slight shifts are due to coordination) under identical excitation conditions.

In the case of solid 4, the detected emission spectrum seems to arise mainly from the mepaoH ligand and not from $\mathrm{Tb}^{\mathrm{III}}$; this was rather expected since $\mathrm{Tb}^{\mathrm{III}}$ ions' characteristic emission peaks are in the same spectral area [41,72].

Complexes of some $\mathrm{Ln}^{\mathrm{III}}$ ions are currently protagonists in several areas of molecular magnetism [71,73-83]. The paramagnetic nature of most $\mathrm{Ln}^{\mathrm{III}}$ ions arises from their large number of unpaired $4 \mathrm{f}$ electrons (large ground-state spin). This property combined with the magnetic anisotropy of some complexes can lead to Single-Molecule Magnetism (SMM) behavior [76-83]. Single-Molecule Magnets (SMMs) are today at the forefront of new technological advances, e.g., in quantum information processing and spintronics [71]. The goal of this work is not associated with the study of the magnetic properties of $\mathrm{Ln}(\mathrm{III}) /$ mepaoH complexes. A full magnetic study of $\sim 20$ carboxylato-bridged dinuclear $\mathrm{Tb}(\mathrm{III}), \mathrm{Dy}(\mathrm{III}), \mathrm{Ho}(\mathrm{III}), \mathrm{Er}(\mathrm{III})$, and $\mathrm{Yb}(\mathrm{III})$ complexes with the four capping ligands shown in Figure 1, including the field-induced SMM behavior of some of them, will be reported 
in a separate work (currently in preparation). Here, we simply describe the magnetic properties of 3 , which contains $\mathrm{Gd}^{\mathrm{III}}$ centers that present no spin-orbit coupling at the first order.

Direct-current $(\mathrm{dc})$ molar magnetic susceptibility $\left(\chi_{\mathrm{M}}\right)$ data on a polycrystalline sample of 3 were collected in the $2.0-300 \mathrm{~K}$ range using an applied field of $0.1 \mathrm{~T}$; the data are presented in the $\chi_{\mathrm{M}} T$ vs. $T$ plot in Figure 10, where $T$ is the absolute temperature. At room temperature, the $\chi_{\mathrm{M}} T$ value of 3 is $16.02 \mathrm{~cm}^{3} \cdot \mathrm{K} \cdot \mathrm{mol}^{-1}$, in very good agreement with the expected theoretical value of $15.75 \mathrm{~cm}^{3} \cdot \mathrm{K} \cdot \mathrm{mol}^{-1}$ for two noninteracting $\mathrm{Gd} \mathrm{d}^{\mathrm{III}}$ centers $(S=7 / 2, L=0, g=2.00)$. The value of $\chi_{\mathrm{M}} T$ remains almost constant in the $50-300 \mathrm{~K}$ range and then decreases rapidly with decreasing $T$ to reach a value of $11.05 \mathrm{~cm}^{3} \cdot \mathrm{K} \cdot \mathrm{mol}^{-1}$ at $2.0 \mathrm{~K}$; this decrease directly reveals the presence of weak antiferromagnetic, intramolecular $\mathrm{Gd}^{\mathrm{III}} \ldots \mathrm{Gd}^{\mathrm{III}}$ exchange interactions. The experimental data were fitted to the van Vleck analytical expression of the susceptibility derived from the isotropic Heisenberg spin Hamiltonian of Equation (5). The best-fit parameters obtained are $J=-0.09(1) \mathrm{cm}^{-1}$ and $g=2.02$. Because of the little overlap between the shielded $4 \mathrm{f}$ orbitals and the orbitals of the bridging oxygen atoms, the observed antiferromagnetic exchange interaction is very weak. Such small values have been observed in systems containing symmetrically bridged $\left\{\mathrm{Gd}^{\mathrm{III}}{ }_{2}\left(\mu_{2}-\mathrm{OR}^{\prime \prime}\right)_{2}\right\}$ cores $\left(\mathrm{R}^{\prime \prime}=\right.$ various groups $)[38,40,42,84-86]$.

$$
\hat{H}=-J\left(\hat{S}_{G d 1} \cdot \hat{S}_{G d 2}\right)
$$

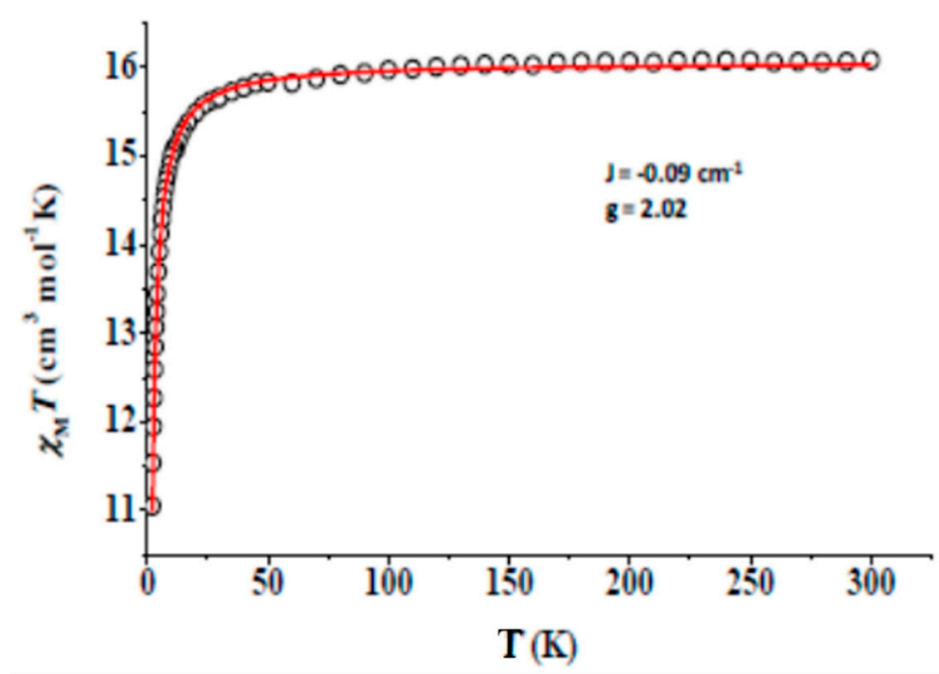

Figure 10. Temperature dependence of the $\chi_{\mathrm{M}} T$ product of complex 3 at $0.1 \mathrm{~T}$. The solid red line is the fit of the data to the theoretical Heisenberg model for a $\mathrm{Gd}^{\mathrm{III}} 2$ complex; see the text for details.

\section{Experimental Section}

\subsection{Materials, Physical and Spectroscopic Measurements}

All manipulations were performed under aerobic conditions. Reagents and solvents were purchased from Alfa Aesar (Karlsruhe, Germany) and Sigma-Aldrich (Tanfrichen, Germany), and used as received. The free ligand methyl 2-pyridyl ketoxime (mepaoH; $\mathrm{R}=\mathrm{Me}$ in Figure 1) was synthesized as described in the literature [87] in $>70 \%$ yields; its purity was checked by ${ }^{1} \mathrm{H}$ NMR spectroscopy and the determination of its melting point (found, $118-119{ }^{\circ} \mathrm{C}$; reported, $121^{\circ} \mathrm{C}$ ).

Elemental analyses $(\mathrm{C}, \mathrm{H}, \mathrm{N})$ were performed by the University of Patras Center of Instrumental Analysis. FT-IR spectra $\left(4000-450 \mathrm{~cm}^{-1}\right)$ were recorded using a PerkinElmer 16PC spectrometer (PerkinElmer, Watham, MA, USA) with samples prepared as $\mathrm{KBr}$ pellets under pressure. Solid-state emission and excitation spectra were recorded at room temperature using a Cary Eclipse fluorescence spectrometer (Varian, Palo Alto, CA, USA). Variable-temperature, solid-state direct current (dc) magnetic susceptibility data in the 
2.0-300 K range were collected on a Quantum Design MPMS-XL SQUID magnetometer (Quantum Design, San Diego, CA, USA) operating at $0.1 \mathrm{~T}$ housed at the University of Crete. The magnetic data were corrected for the intrinsic diamagnetic contributions using Pascal's constants [88].

\subsection{Synthesis of the Representative Complex $\left[\mathrm{Nd}_{2}\left(\mathrm{O}_{2} \mathrm{CMe}\right)_{4}\left(\mathrm{NO}_{3}\right)_{2}(\text { mepaoH })_{2}\right](\mathbf{1})$}

Method (a): To a stirred colorless solution of mepaoH (0.136 g, $1.00 \mathrm{mmol})$ in $\mathrm{MeCN}$ $(10 \mathrm{~mL})$, solid $\mathrm{Nd}\left(\mathrm{NO}_{3}\right)_{3} \cdot 6 \mathrm{H}_{2} \mathrm{O}(0.219 \mathrm{~g}, 0.50 \mathrm{mmol})$ was added. The solid soon dissolved and the resulting pale lilac solution was stirred for a further $30 \mathrm{~min}$, and filtered and stored in a closed flask at room temperature. X-ray quality, almost colorless crystals of the product, were precipitated within a period of one week. The crystals were collected by filtration, washed with cold $\mathrm{MeCN}(2 \times 1 \mathrm{~mL})$ and $\mathrm{Et}_{2} \mathrm{O}(3 \times 2 \mathrm{~mL})$, and dried in air overnight, Yield: $34 \%$ (based on the $\mathrm{Nd}^{\mathrm{III}}$ available). Anal. Calcd. (\%) for $\mathrm{C}_{22} \mathrm{H}_{28} \mathrm{Nd}_{2} \mathrm{~N}_{6} \mathrm{O}_{16}: \mathrm{C}, 28.69 ; \mathrm{H}$, 3.07; N, 9.13. Found (\%): C, 28.81; H, 2.99; N, 8.93. Selected IR data $\left(\mathrm{KBr}, \mathrm{cm}^{-1}\right): 3260 \mathrm{mb}$, $1590 \mathrm{~s}, 1492 \mathrm{~s}, 1420 \mathrm{~s}, 1295 \mathrm{~s}, 1130 \mathrm{~m}, 1090 \mathrm{~m}, 1020 \mathrm{~s}, 960 \mathrm{~m}, 791 \mathrm{~s}, 682 \mathrm{~s}, 410 \mathrm{~m}$.

Method (b): To a stirred colorless solution containing mepaoH $(0.136 \mathrm{~g}, 1.00 \mathrm{mmol})$, glacial $\mathrm{MeCO}_{2} \mathrm{H}(0.173 \mathrm{~mL}, 3.00 \mathrm{mmol})$ and $\mathrm{Et}_{3} \mathrm{~N}(0.390 \mathrm{~mL}, 3.00 \mathrm{mmol})$ in $\mathrm{MeCN}(15 \mathrm{~mL})$, solid $\mathrm{Nd}\left(\mathrm{NO}_{3}\right)_{3} \cdot 6 \mathrm{H}_{2} \mathrm{O}(0.219 \mathrm{~g}, 0.50 \mathrm{mmol})$ was added. The solid soon dissolved and the resulting pale lilac solution was stirred for a further $30 \mathrm{~min}$, and filtered and stored in a closed flask at room temperature. X-ray, almost colorless crystals were precipitated within a period of $4-5 \mathrm{~d}$. The crystals were collected by filtration, washed with cold $\mathrm{MeCN}$ $(4 \times 2 \mathrm{~mL})$ and $\mathrm{Et}_{2} \mathrm{O}(4 \times 2 \mathrm{~mL})$, and dried in air overnight. Yield: $27 \%$ (based on the $\mathrm{Nd}^{\mathrm{III}}$ available). Anal. Calcd. (\%) for $\mathrm{C}_{22} \mathrm{H}_{28} \mathrm{Nd}_{2} \mathrm{~N}_{6} \mathrm{O}_{16}: \mathrm{C}, 28.69 ; \mathrm{H}, 3.07 ; \mathrm{N}, 9.13$. Found (\%): $\mathrm{C}$, $28.43 ; \mathrm{H}, 3.17 ; \mathrm{N}, 8.99$. The IR spectrum of the solid sample was identical with the authentic sample obtained by method (a).

3.3. Syntheses of the Complexes $\left[\mathrm{Eu}_{2}\left(\mathrm{O}_{2} \mathrm{CMe}\right)_{4}\left(\mathrm{NO}_{3}\right)_{2}(\text { mepaoH })_{2}\right](\mathbf{2})$,

$\left[\mathrm{Gd}_{2}\left(\mathrm{O}_{2} \mathrm{CMe}\right)_{4}\left(\mathrm{NO}_{3}\right)_{2}(\text { mepaoH })_{2}\right](3),\left[\mathrm{Tb}_{2}\left(\mathrm{O}_{2} \mathrm{CMe}\right)_{4}\left(\mathrm{NO}_{3}\right)_{2}(\text { mepaoH })_{2}\right]$ (4) and $\left[\mathrm{Dy} \mathrm{y}_{2}\left(\mathrm{O}_{2} \mathrm{CMe}\right)_{4}\left(\mathrm{NO}_{3}\right)_{2}(\text { mераoH })_{2}\right]$ (5)

These compounds were prepared in an identical manner with 1 , by using both of the above-mentioned methods, by simply replacing $\mathrm{Nd}\left(\mathrm{NO}_{3}\right)_{3} \cdot 6 \mathrm{H}_{2} \mathrm{O}$ with the corresponding hydrated nitrate salts of $\mathrm{Eu}(\mathrm{III}), \mathrm{Gd}(\mathrm{III}), \mathrm{Tb}(\mathrm{III})$ and Dy(III). Typical yields were $\sim 35 \%$ using method (a) and $\sim 25 \%$ using method (b). The cited experimental microanalyses values are from samples prepared by method (a). Anal. Calcd. (\%) for $\mathrm{C}_{22} \mathrm{H}_{28} \mathrm{Eu}_{2} \mathrm{~N}_{6} \mathrm{O}_{16}$ (2): $\mathrm{C}, 28.21 ; \mathrm{H}, 3.02 ; \mathrm{N}, 8.98$. Found (\%): C, 28.43; H, 2.95; N, 8.67. Anal. Calcd. (\%) for $\mathrm{C}_{22} \mathrm{H}_{28} \mathrm{Gd}_{2} \mathrm{~N}_{6} \mathrm{O}_{16}$ (3): $\mathrm{C}, 27.90 ; \mathrm{H}, 2.99 ; \mathrm{N}$, 8.89. Found (\%): $\mathrm{C}, 27.77 ; \mathrm{H}, 3.04 ; \mathrm{N}, 8.71$. Anal. Calcd. (\%) for $\mathrm{C}_{22} \mathrm{H}_{28} \mathrm{~Tb}_{2} \mathrm{~N}_{6} \mathrm{O}_{16}$ (4): C, 27.80; H, 2.98; N, 8.84. Found (\%): C, 28.12; H, 2.84; $\mathrm{N}$, 9.04. Anal. Calcd. (\%) for $\mathrm{C}_{22} \mathrm{H}_{28} \mathrm{Dy}_{2} \mathrm{~N}_{6} \mathrm{O}_{16}$ (5): C, 27.59; H, 2.95; N, 8.78. Found (\%): C, $27.81 ; \mathrm{H}, 3.04 ; \mathrm{N}, 8.70$. The IR spectra of $\mathbf{2}-\mathbf{5}$ are almost superimposable with the spectrum of 1 with a maximum wavenumber of $\pm 4 \mathrm{~cm}^{-1}$.

\subsection{Synthesis of $\left[\mathrm{Dy}{ }_{2}\left(\mathrm{O}_{2} \mathrm{CMe}\right)_{6}(\text { mepaoH })_{2}\right](6)$}

To a stirred colorless solution of mepaoH $(0.136 \mathrm{~g}, 1.00 \mathrm{mmol})$ in a solvent mixture comprising $\mathrm{MeOH}(5 \mathrm{~mL})$ and $\mathrm{MeCN}(10 \mathrm{~mL})$, solid $\mathrm{Dy}\left(\mathrm{O}_{2} \mathrm{CMe}_{3} \cdot 4 \mathrm{H}_{2} \mathrm{O}(0.215 \mathrm{~g}, 0.50 \mathrm{mmol})\right.$ was added. The reaction mixture was stirred under reflux overnight and the obtained slurry was filtered to remove a small quantity of solid. The filtrate was kept in a closed vial at room temperature. X-ray quality, colorless crystals of the product were precipitated within a period of $24 \mathrm{~h}$. The crystals were collected by filtration, washed with cold $\mathrm{MeOH}$ $(1 \mathrm{~mL}), \mathrm{MeCN}(1 \mathrm{~mL})$ and $\mathrm{Et}_{2} \mathrm{O}(3 \times 1 \mathrm{~mL})$, and dried in air. The yield was $55 \%$ (based on the available Dy ${ }^{\mathrm{III}}$ ). Anal. Calcd. (\%) for $\mathrm{C}_{26} \mathrm{H}_{34} \mathrm{Dy}_{2} \mathrm{~N}_{4} \mathrm{O}_{14}$ : C, 32.81; $\mathrm{H}, 3.61 ; \mathrm{N}, 5.89$. Found (\%): C, 32.99; H, 3.44; N, 5.72. Selected IR data $\left(\mathrm{KBr}, \mathrm{cm}^{-1}\right): 3255 \mathrm{mb}, 1593 \mathrm{~s}, 1540 \mathrm{~s}$, $1465 \mathrm{~m}, 1418 \mathrm{~s}, 1128 \mathrm{~m}, 1085 \mathrm{~m}, 1023 \mathrm{~s}, 793 \mathrm{~s}, 680 \mathrm{~s}, 410 \mathrm{~m}$. 


\subsection{Conversion of $\mathbf{6}$ to $\mathbf{5}$}

A slurry of $\left[\mathrm{Dy}_{2}\left(\mathrm{O}_{2} \mathrm{CMe}\right)_{6}(\mathrm{mepaoH})_{2}\right](6)(0.285 \mathrm{~g}, 0.30 \mathrm{mmol})$ in $\mathrm{MeCN}$ was treated in the hood with $2 \mathrm{~N} \mathrm{HNO}_{3}\left(0.35 \mathrm{~mL}, 0.70 \mathrm{mmol} \mathrm{HNO}_{3}\right)$. The resulting slurry was stirred overnight and the resulting powder was filtered, washed with $\mathrm{MeCN}(2 \times 1 \mathrm{~mL})$ and dried in a vacuum desiccator over $\mathrm{P}_{4} \mathrm{O}_{10}$. The yield was $\sim 70 \%$ (based on 6). Anal. Calcd. (\%) for $\mathrm{C}_{22} \mathrm{H}_{28} \mathrm{Dy}_{2} \mathrm{~N}_{6} \mathrm{O}_{16}$ (5): $\mathrm{C}, 27.59 ; \mathrm{H}, 2.95 ; \mathrm{N}, 8.78$. Found (\%): C, 28.04; H, 2.86; N, 8.51. The IR spectrum of the dried white powder is identical with that of the authentic complex 5 .

\subsection{Single-Crystal X-ray Crystallography}

Colorless crystals of $\mathbf{1}(0.08 \times 0.09 \times 0.30 \mathrm{~mm}), \mathbf{5}(0.10 \times 0.16 \times 0.18 \mathrm{~mm})$ and $\mathbf{6}$ $(0.10 \times 0.13 \times 0.15 \mathrm{~mm})$ were taken from the mother liquor and immediately cooled to $-113{ }^{\circ} \mathrm{C}(160 \mathrm{~K})$. Diffraction data were collected on a Rigaku R-AXIS SPIDER Image Plate diffractometer (Rigaku Americas Corporation, The Woodlands, TX, USA; European Department at Karlsruhe, Germany) using graphite-monochromated $\mathrm{Cu} \mathrm{K} \alpha$ radiation. Data collection ( $\omega$-scans) and processing (cell refinement, data reduction, and empiri$\mathrm{cal} /$ numerical absorption correction) were performed using the CrystalClear program package [89]. The structures were solved by direct methods using SHELXS, ver. 2013/1 [90] and refined by full-matrix least-squares techniques of $F^{2}$ with SHELXL, ver. 2014/ 6 [91]. All non-H atoms were refined anisotropically. All $\mathrm{H}$ atoms were introduced at calculated positions as riding on their corresponding bonded atoms. Structural plots were drawn using the Diamond 3 program package [92]. Crystallographic data are summarized in Table S1.

Crystallographic data have been deposited with the Cambridge Crystallographic Data Center, Nos 2059448 (1), 2059447 (5) and 2059449 (6). Copies of the data can be obtained free of charge upon application to CCDC, 12 Union Road, Cambridge, CB2 1EZ, UK: Tel.: +(44)-1223-762910; Fax: +(44)-1223-336033; E-mail: deposit@ccdc.cam.ac.uk, or via http:/ / www.ccdc.cam.ac.uk/conts/retrieving.html.

\section{Concluding Comments and Perspectives}

In this work, we have shown that the first use of methyl 2-pyridyl ketoxime (mepaoH) in homometallic $\operatorname{Ln}(\mathrm{III})$ chemistry has provided access to complexes containing the $\left\{\operatorname{Ln}_{2}^{\mathrm{III}}{ }_{2}\left(\eta^{1}\right.\right.$ : $\left.\left.\eta^{1}: \mu_{2}\right)_{2}\left(\eta^{1}: \eta^{2}: \mu_{2}\right)_{2}\right\}^{2+}$ unit, and one chelating mepaoH ligand and one chelating nitrato (1-5) or acetato (6) group per metal ion. Although the crystal structures of only three complexes $(1,5,6)$ have been solved by single-crystal X-ray crystallography revealing interesting molecular and supramolecular features, and, despite the fact that we do not have on hand powder XRD patterns for 2, 3, and 4, the spectroscopic and analytical evidence suggests similar structures for the $\mathrm{Eu}(\mathrm{III}), \mathrm{Gd}(\mathrm{III})$, and $\mathrm{Tb}(\mathrm{III})$ complexes.

The most salient chemical features of the present work are: (a) the acetato ligands in 1-5 arise from the rare $\mathrm{Ln}^{\mathrm{III}}$-mediated hydrolysis of the solvent used in the reactions $(\mathrm{MeCN})$; and (b) the mixed acetato/nitrato complexes 1-5 are the thermodynamically preferred products from the $\mathrm{Ln}^{\mathrm{III}} / \mathrm{NO}_{3}{ }^{-} / \mathrm{MeCO}_{2}{ }^{-} /$mepaoH reaction systems and that the all-acetato complex $\left[\mathrm{Dy}_{2}\left(\mathrm{O}_{2} \mathrm{CMe}\right)_{6}(\mathrm{mepaoH})_{2}\right](6)$ can be obtained only in the absence of nitrates. We have also demonstrated that the coordination of mepaoH to $\mathrm{Eu}^{\mathrm{III}}$ leads to a complex that emits red light coming from the enhanced emission of $\mathrm{Eu}(\mathrm{III})$. This can be attributed mainly to the shielding of the metal ion from $\mathrm{H}_{2} \mathrm{O}$ ligands (the presence of aqua ligands quenches the emission significantly). The $\mathrm{Tb}^{\mathrm{III}}$ center in 4 emits in the same region with the ligand and thus the characteristic ${ }^{5} D_{4} \rightarrow{ }^{7} F_{j}(j=3-6)$ green emission pattern of this metal ion was not observed. In addition, the magnetic study of 3 suggests weak antiferromagnetic intramolecular $\mathrm{Gd}^{\mathrm{III}} \cdots \mathrm{Gd}^{\mathrm{III}}$ exchange interaction.

We do believe that the research theme presented here is not exhausted of new interesting results. The terminal nitrato (1-5) or acetato (6) groups might have utility as a means to obtain higher-nuclearity neutral or ionic $\mathrm{Ln}^{\mathrm{III}} / \mathrm{MeCO}_{2}{ }^{-} /$mepaoH clusters and/or polymeric species, by replacing them with bis(bidentate) bridging ligands, e.g., aromatic heterocycles or dicarboxylates; such reactivity could alter the photophysical 
properties of the resulting complexes. The ability of mepaoH to act as an anionic ligand $\left(\mathrm{mepao}^{-}\right)$bridging two or three metal ions gives us the stimulus to try to prepare polynuclear $\mathrm{Ln}^{\mathrm{III}} / \mathrm{mepao}^{-}$/ clusters. In addition, we have been working with the analogues of mepaoH ( $\mathrm{R}=\mathrm{H}, \mathrm{Ph}, \mathrm{Cl}$ in Figure 1$)$ to study the influence of $\mathrm{R}$ on the identity and properties of the products. Last, but not least, inspired by the recent advances in the field of opto-magnetic materials and especially in that of optical thermometers (Single-Molecule Magnets which display thermally controlled luminescence) $[93,94]$, we are investigating the optical/magnetic properties of 4-6 and analogous dinuclear $\operatorname{Ln}(\mathrm{III})$ complexes with a variety of other neutral 2-pyridyl oximes as capping ligands. Some of the above-mentioned efforts are already well-advanced proving that we have only scratched the surface of the lanthanide(III)/2-pyridyl oxime chemistry, and our results will be reported soon.

Supplementary Materials: The following are available online, Figure S1: Coordination polyhedra of lanthanide(III) centers in complexes 1, 5, and 6. Figure S2: ORTEP-type plots of the dinuclear molecules in 1 and 5 illustrating the intramolecular H bonds. Figure S3: ORTEP-type plot of the dinuclear molecule in 6 illustrating the intramolecular $\mathrm{H}$ bonds. Table S1: Crystallographic data for complexes 1, 5, and 6. Table S2: CShM values for the potential polyhedra of the lanthanide(III) centers in 1, 5, and 6. Table S3: Distances and angles of the intra-and intermolecular H-bonding interactions in the crystal structures of complexes 1 and 5. Table S4: Distances and angles of the intraand intermolecular H-bonding interactions in the crystal structure of complex 6.

Author Contributions: C.D.P. and H.N. contributed towards the syntheses, crystallization of the complexes, as well as the interpretation of the relevant results; C.P.R. and V.P. collected single-crystal $X$-ray diffraction data, solved the structures, and performed their refinements; the latter also studied in depth the supramolecular features of the crystal structures and wrote the relevant part of the article. V.B. and K.F.K. recorded and interpreted the solid-state, room-temperature excitation and emission spectra of the $\mathrm{Eu}(\mathrm{III})$ and $\mathrm{Tb}(\mathrm{III})$ complexes. S.P.P. coordinated the research and wrote the paper based on the reports of his collaborators. All authors exchanged opinions concerning the progress of the project and commented on the preparation of the manuscript at all steps. All authors have read and agreed to the published version of this manuscript.

Funding: S.P.P. thanks the COST Action CA15128 -Molecular Spintronics (MOLSPIN) for travel grants and for encouraging research activities in Patras, Greece.

Institutional Review Board Statement: Not applicable.

Informed Consent Statement: Not applicable.

Data Availability Statement: Crystallographic information files are available through the CCDC following the assigned numbers. The data presented here are available on request to the corresponding authors.

Acknowledgments: We thank C.J. Milios for collecting the variable-temperature magnetic susceptibility data for compound 3 and his contribution to interpret the results.

Conflicts of Interest: The authors declare no conflict of interest.

Sample Availability: Samples of the compounds presented in this study are available on request to the corresponding authors.

\section{References}

1. Gerasimchuk, N. Recent Advances in Chemistry and Applications of Oximes and their Metal Complexes: Parts I and II. Curr. Inorg. Chem. 2015, 5, 82. [CrossRef]

2. Tschugaeff, L. Ueber ein neues, empfindliches reagens auf nickel. Ber. Dtsch. Chem. 1905, 38, 2520-2522. [CrossRef]

3. Thorpe, J.M.; Beddoes, R.L.; Collison, D.; Garner, C.D.; Helliwell, M.; Holmes, J.M.; Tasker, P.A. Surface coordination chemistry. Corrosion inhibition by tetranuclear cluster formation of iron with salicyladoxime. Angew. Chem. Int. Ed. 1999, 38, $1119-1121$. [CrossRef]

4. Tasker, P.A.; Tong, C.C.; Westra, A.N. Co-extraction of cations and anions in base metal recovery. Coord. Chem. Rev. 2007, 251, 1868-1877. [CrossRef]

5. Gerasimchuk, N. Chemistry and applications of cyanoximes and their metal complexes. Dalton Trans. 2019, 48, 7985-8013. [CrossRef] [PubMed] 
6. Gerasimchuk, N.; Maher, T.; Durham, P.; Domasevitch, K.V.; Wilking, J.; Mokhir, A. Tin(IV) Cyanoximates: Synthesis, Characterization, and Cytotoxicity. Inorg. Chem. 2007, 46, 7268-7284. [CrossRef]

7. Pettenuzzo, A.; Pigot, R.; Ronconi, L. Vitamin B12-Metal Conjugates for Targeted Chemotherapy and Diagnosis: Current Status and Future Prospects. Eur. J. Inorg. Chem. 2017, 2017, 1625-1638. [CrossRef]

8. Perlepe, P.S.; Maniaki, D.; Pilichos, E.; Katsoulakou, E.; Perlepes, S.P. Smart Ligands for Efficient 3d-, 4d- and 5d-Metal SingleMolecule Magnets and Single-Ion Magnets. Inorganics 2020, 8, 39. [CrossRef]

9. Chaudhuri, P. Homo- and hetero-polymetallic exchange coupled metal-oximates. Coord. Chem. Rev. 2003, 243, 143-190. [CrossRef]

10. Yang, C.-I.; Zhang, Z.-Z.; Lin, S.-B. A review of manganese-based molecular magnets and supramolecular architectures from phenolic oximes. Coord. Chem. Rev. 2015, 289-290, 289-314. [CrossRef]

11. Milios, C.J.; Inglis, R.; Vinslava, A.; Bagai, R.; Wernsdorfer, W.; Parsons, S.; Perlepes, S.P.; Christou, G.; Brechin, E.K. Toward a Magnetostructural Correlation for a Family of $\mathrm{Mn}_{6}$ SMMs. J. Am. Chem. Soc. 2007, 129, 12505-12511. [CrossRef]

12. Alonso, D.A.; Nájera, C. Oxime-derived palladacycles as source of palladium nanoparticles. Chem. Soc. Rev. 2010, 39, 2891-2902. [CrossRef] [PubMed]

13. Kopylovich, M.N.; Kukushkin, V.Y.; Haukka, M.; Fráusto da Silva, J.J.R.; Pombeiro, A.J.L. Zinc(II)/Ketoxime System as a Simple and Efficient Catalyst for Hydrolysis of Organonitriles. Inorg. Chem. 2002, 41, 4798-4804. [CrossRef] [PubMed]

14. Kukushkin, V.Y.; Pombeiro, A.J.L. Oxime and oximate metal complexes: Unconventional synthesis and reactivity. Coord. Chem. Rev. 1999, 181, 147-175. [CrossRef]

15. Garnovskii, D.A.; Kukushkin, V.Y. Metal-mediated reactions of oximes. Russ. Chem. Rev. 2006, 75, 111-124. [CrossRef]

16. Bolotin, D.S.; Bokach, N.A.; Demakova, M.Y.; Kukushkin, V.Y. Metal-Involving Synthesis and Reaction of Oximes. Chem. Rev. 2017, 17, 13039-13122. [CrossRef]

17. Milios, C.J.; Stamatatos, T.C.; Perlepes, S.P. The coordination chemistry of pyridyl oximes. Polyhderon 2006, 25, 134-194. [CrossRef]

18. Polyzou, C.D.; Nikolaou, H.; Papatriantafyllopoulou, C.; Psycharis, V.; Terzis, A.; Raptopoulou, C.P.; Escuer, A.; Perlepes, S.P. Employment of methyl 2-pyridyl Ketone oxime in 3d/4f-metal chemistry: Dinuclear nickel(II)/lanthanide(III) species and complexes containing the metals in separate ions. Dalton Trans. 2012, 41, 13755-13764. [CrossRef]

19. Anastasiadis, N.C.; Polyzou, C.D.; Kostakis, G.E.; Bekiari, V.; Lan, Y.; Perlepes, S.P.; Konidaris, K.F.; Powell, A.K. Dinuclear lanthanide(III)/zinc(II) complexes with methyl 2-pyridyl ketone oxime. Dalton Trans. 2015, 44, 19791-19795. [CrossRef]

20. Polyzou, C.D.; Koumousi, E.S.; Lada, Z.G.; Raptopoulou, C.P.; Psycharis, V.; Rouzières, M.; Tsipis, A.C.; Mathonière, C.; Clérac, R.; Perlepes, S.P. "Switching on" the single-molecule magnet properties within a series of dinuclear cobalt(III)-dysprosium(III) 2-pyridyloximate complexes. Dalton Trans. 2017, 46, 14812-14825. [CrossRef] [PubMed]

21. Tsantis, S.T.; Zagoraiou, E.; Savvidou, A.; Raptopoulou, C.P.; Psycharis, V.; Szyrwiel, L.; Holyńska, M.; Perlepes, S.P. Binding of oxime group to uranyl ion. Dalton Trans. 2016, 45, 9307-9319. [CrossRef]

22. Stamatatos, T.C.; Foguet-Albiol, D.; Lee, S.-C.; Stoumpos, C.C.; Raptopoulou, C.P.; Terzis, A.; Wernsdorfer, W.; Hill, S.O.; Perlepes, S.P.; Christou, G. "Switching On" the Properties of Single-Molecule Magnetism in Triangular Manganese(III) Complexes. J. Am. Chem. Soc. 2007, 129, 9484-9499. [CrossRef] [PubMed]

23. Konidaris, K.F.; Bekiari, V.; Katsoulakou, E.; Raptopoulou, C.P.; Psycharis, V.; Manessi-Zoupa, E.; Kostakis, G.E.; Perlepes, S.P. Investigation of the zinc(II)-benzoate-2-pyridylaldoxime reaction system. Dalton Trans. 2012, 41, 3797-3806. [CrossRef] [PubMed]

24. Stamatatos, T.C.; Katsoulakou, E.; Terzis, A.; Raptopoulou, C.P.; Winpenny, R.E.P.; Perlepes, S.P. A family of mononuclear $\mathrm{Co}^{\mathrm{III}}$ /2-pyridyloximate complexes and their conversion to trinuclear, mixed-valence linear $\mathrm{Co}^{\mathrm{II} / \mathrm{III}}{ }_{3}$ clusters. Polyhedron 2009, 28, 1638-1645. [CrossRef]

25. Stamatatos, T.C.; Escuer, A.; Abboud, K.A.; Raptopoulou, C.P.; Perlepes, S.P.; Christou, G. Unusual Structural Types in Nickel Cluster Chemistry from the Use of Pyridyl Oximes: $\mathrm{Ni}_{5}, \mathrm{Ni}_{12} \mathrm{Na}_{2}$ and $\mathrm{Ni}_{14}$ Clusters. Inorg. Chem. 2008, 47, 11825-11838. [CrossRef]

26. Anastasiadis, N.C.; Lada, Z.G.; Polyzou, C.D.; Raptopoulou, C.P.; Psycharis, V.; Konidaris, K.F.; Perlepes, S.P. Synthetic strategies to $\left\{\mathrm{Co}_{2}{ }_{2} \mathrm{Ln}\right\}$ complexes based on 2-pyridyl oximes ( $\mathrm{Ln}=$ lanthanide). Inorg. Chem. Commun. 2019, 108, 104478. [CrossRef]

27. Tzani, S.; Lazarou, K.N.; Stoumpos, C.C.; Pissas, M.; Psycharis, V.; Sanakis, Y.; Raptopoulou, C.P. Iron (III) complexes with 2-pyridyl oxime ligands: Synthesis, structural and spectroscopic characterization, and magnetic studies. ChemistrySelect 2016, 2, 147-156. [CrossRef]

28. Konidaris, K.F.; Polyzou, C.D.; Kostakis, G.E.; Tasiopoulos, A.J.; Roubeau, O.; Teat, S.J.; Manessi-Zoupa, E.; Powell, A.K.; Perlepes, S.P. Metal ion-assisted transformations of 2-pyridinealdoxime and hexafluorophosphate. Dalton Trans. 2012, 41, 2862-2865. [CrossRef]

29. Milios, C.J.; Kefalloniti, E.; Raptopoulou, C.P.; Terzis, A.; Escuer, A.; Vicente, R.; Perlepes, S.P. 2-pyridinealdoxime [(py)CHNOH] in manganese(II) carboxylate chemistry: Mononuclear, dinuclear, tetranuclear and polymeric complexes, and partial transformation of (py)CHNOH to picolinate(-1). Polyhedron 2004, 23, 83-95. [CrossRef]

30. Tsantis, S.T.; Bekiari, V.; Tzimopoulos, D.I.; Raptopoulou, C.P.; Psycharis, V.; Tsipis, A.; Perlepes, S.P. Reactivity of Coordinated 2-Pyridyl Oximes: Synthesis, Structure, Spectroscopic Characterization and Theroretical Studies of Dichlorodi $\{(2-$ pyridyl)Furoxan\}Zinc(II) Obtained from the Reaction between Zinc(II) Nitrate and Pyridine-2-Chloroxime. Inorganics 2020,8 , 47. [CrossRef]

31. Mazarakioti, E.C.; Soto Beobide, A.; Angelidou, V.; Eftymiou, C.G.; Terzis, A.; Psycharis, V.; Voyiatzis, G.A.; Perlepes, S.P. Modeling the Solvent Extraction of Cadmium(II) from Aqueous Chloride Solutions by 2-pyridyl Ketoximes: A Coordination Chemistry Approach. Molecules 2019, 24, 2219. [CrossRef] 
32. Danelli, P.; Lada, Z.G.; Raptopoulou, C.P.; Psycharis, V.; Stamatatos, T.C.; Perlepes, S.P. Doubly Thiocyanato(S,N)-Bridged Dinuclear Complexes of Mercury(II) from the Use of 2-pyridyl Oximes as Capping Ligands. Current Inorg. Chem. 2015, 5, 26-37. [CrossRef]

33. Yang, H. Trichloridotris $\left\{\mathrm{N}-\left[\right.\right.$ phenyl(pyridin-2-yl)methylidene]hydroxylamine- $\left.\mathrm{k}^{2} \mathrm{~N}, \mathrm{~N}^{\prime}\right\}$ neodymium(III). Acta Crystallogr. Sect. E 2012, 68, m578-m579. [CrossRef]

34. Lei, T.; Chen, W.; Chen, Y.; Hu, B.; Li, Y. Trichloridotris\{N-[phenyl(pyridin-2-yl)methylidene]hydroxylamine-k $\left.{ }^{2} \mathrm{~N}, \mathrm{~N}^{\prime}\right\}$ samarium(III) Acta Crystallogr. Sect. E 2012, 68, m344-m345. [CrossRef] [PubMed]

35. Maniaki, D.; Perlepes, S.P.; Pilichos, E.; Christodoulou, S.; Rouzières, M.; Dechambenoit, P.; Clérac, R.; Perlepes, S.P. Asymmetric Dinuclear Lanthanide(III) Complexes from the Use of a Ligand Derived from 2-Acetylpyridine and Picolinohydrazide: Synthetic, Structural and Magnetic Studies. Molecules 2020, 25, 3153. [CrossRef] [PubMed]

36. Anastasiadis, N.C.; Granadeiro, C.M.; Mayans, J.; Raptopoulou, C.P.; Bekiari, V.; Cunha-Silva, L.; Psycharis, V.; Escuer, A.; Balula, S.S.; Konidaris, K.F.; et al. Multifunctionality in Two Families of Dinuclear Lanthanide(III) Complexes with a Tridentate Schiff-Base Ligand. Inorg. Chem. 2019, 58, 9581-9585. [CrossRef] [PubMed]

37. Pilichos, E.; Mylonas-Margaritis, I.; Kontos, A.P.; Psycharis, V.; Klouras, N.; Raptopoulou, C.P.; Perlepes, S.P. Coordination and metal ion-mediated transformation of a polydentate ligand containing oxime, hydrazone and picolinoyl functionalities. Inorg. Chem. Commun. 2018, 94, 48-52. [CrossRef]

38. Mylonas-Margaritis, I.; Mayans, J.; Sakellakou, S.-M.; Raptopoulou, C.P.; Psycharis, V.; Escuer, A.; Perlepes, S.P. Using the Singly Deprotonated Triethanolamine to Prepare Dinuclear Lanthanide(III) Complexes: Synthesis, Structural Characterization and Magnetic Studies. Magnetochemistry 2017, 3, 5. [CrossRef]

39. Anastasiadis, N.C.; Mylonas-Margaritis, I.; Psycharis, V.; Raptopoulou, C.P.; Kalofolias, D.A.; Milios, C.J.; Klouras, N.; Perlepes, S.P. Dinuclear, tetrakis(acetato)-bridged lanthanide(III) complexes from the use of 2-acetylpyridine hydrazone. Inorg. Chem. Commun. 2015, 51, 99-102. [CrossRef]

40. Anastasiadis, N.C.; Kalofolias, D.A.; Philippidis, A.; Tzani, S.; Raptopoulou, C.P.; Psycharis, V.; Milios, C.J.; Escuer, A.; Perlepes, S.P. A family of dinuclear lanthanide(III) complexes from the use of a tridentate Schiff base. Dalton Trans. 2015, 44, 10200-10209. [CrossRef]

41. Nikolaou, H.; Terzis, A.; Raptopoulou, C.P.; Psycharis, V.; Bekiari, V.; Perlepes, S.P. Unique Dinuclear, Tetrakis(nitrato-O,O')Bridged Lanthanide(III) Complexes from the Use of Pyridine-2-Amidoxime: Synthesis, Structural Studies and Spectroscopic Characterization. J. Surf. Interfac. Mater. 2014, 2, 311-318. [CrossRef]

42. Anastasiadis, N.C.; Granadeiro, C.M.; Klouras, N.; Cunha-Silva, L.; Raptopoulou, C.P.; Psycharis, V.; Bekiari, V.; Balula, S.S.; Escuer, A.; Perlepes, S.P. Dinuclear Lanthanide(III) Complexes by Metal-Ion Assisted Hydration of Di-2-pyridyl Ketone Azine. Inorg. Chem. 2013, 52, 4145-4147. [CrossRef]

43. Bekiari, V.; Thiakou, K.A.; Raptopoulou, C.P.; Perlepes, S.P.; Lianos, P. Structure and photophysical behavior of 2,2'bipyrimidine/lanthanide ion complexes in various environments. J. Lumin. 2008, 128, 481-488. [CrossRef]

44. Messimeri, A.; Papadimitriou, C.; Raptopoulou, C.P.; Escuer, A.; Perlepes, S.P.; Boudalis, A.K. The benzoate/nitrate, $2,2^{\prime}: 6^{\prime}, 2^{\prime \prime}-$ terpyridine "blend" in lanthanide(III) chemistry: Relevance to the separation of lanthanides and actinides by solvent extraction. Inorg. Chem. Commun. 2007, 10, 800-804. [CrossRef]

45. Jia, J.-H.; Li, Q.-W.; Chen, Y.-C.; Liu, J.L.; Tong, M.-L. Luminescent single-molecule magnets based on lanthanides: Design strategies, recent advances and magneto-luminescent studies. Coord. Chem. Rev. 2019, 378, 365-381. [CrossRef]

46. Long, J.; Guari, Y.; Ferreira, R.A.S.; Carlos, L.D.; Larionova, J. Recent advances in luminescent lanthanide based Single-Molecule Magnets. Coord. Chem. Rev. 2018, 363, 57-70. [CrossRef]

47. Habib, F.; Murugesu, M. Lessons learned from dinuclear lanthanide nano-magnets. Chem. Soc. Rev. 2013, 42, 3278-3288. [CrossRef]

48. March, J. Advanced Organic Chemistry, 4th ed.; Wiley: New York, NY, USA, 1992; pp. 887-888.

49. Moorthy, J.N.; Singhal, N. Facile and Highly Selective Conversion of Nitriles to Amides via Indirect Acid-Catalyzed Hydration Using TFA or AcOH-H $\mathrm{SO}_{4}$. J. Org. Chem. 2005, 70, 1926-1929. [CrossRef]

50. Constable, E.C. Metals and Ligand Reactivity; VCH: Weinheim, Germany, 1996; pp. 65-72.

51. Raptopoulou, C.P.; Boudalis, A.K.; Sanakis, Y.; Psycharis, V.; Clemente-Juan, J.M.; Fardis, M.; Diamantopoulos, G.; Papavassiliou, G. Hexanuclear Iron(III) Salicylaldoximato Complexes Presenting the $\left[\mathrm{Fe}_{6}\left(\mu_{3}-\mathrm{O}\right)_{2}(\mu-\mathrm{OR})_{2}\right]^{12+}$ Core: Syntheses, Crystal Structures, and Spectroscopic and Magnetic Characterization. Inorg. Chem. 2006, 45, 2317-2326. [CrossRef]

52. Erxleben, A.; Mutikainen, I.; Lippert, B. Conversion of Acetonitrile into Acetamide in the Coordination Spheres of cis- and trans- $\mathrm{M}^{\mathrm{II}}(\text { amine })_{2}(\mathrm{M}=\mathrm{Pt}$ or Pd). Solution and Crystal Structural Studies. J. Chem. Soc. Dalton Trans. 1994, 3667-3675. [CrossRef]

53. Kukushkin, V.Y.; Pombeiro, A.J.L. Additions to Metal-Activated Organonitriles. Chem. Rev. 2002, 102, 1771-1802. [CrossRef]

54. Zhou, X.; Peng, J.-L.; Wen, C.-Y.; Liu, Z.-Y.; Wang, X.-H.; Wu, J.-Z.; Ou, Y.-C. Tuning the structure and Zn(II) sensing of lanthanide complexes with two phenylimidazophenanthrolines by acetonitrile hydrolysis. Cryst. Eng. Commun. 2017, 19, 6533-6539. [CrossRef]

55. Coxall, R.A.; Harris, S.G.; Henderson, D.K.; Parsons, S.; Tasker, P.A.; Winpenny, R.E.P. Inter-ligand reactions: In situ formation of new polydentate ligands. J. Chem. Soc. Dalton Trans. 2000, 2349-2356. [CrossRef]

56. Niu, S.; Yang, Z.; Yang, Q.; Yang, B.; Chao, J.; Yang, G.; Shen, E.Z. Structure and magnetism of tetra acetate bridged binuclear $\mathrm{Nd}^{\mathrm{III}}$ complex. Polyhedron 1997, 16, 1629-1635. [CrossRef] 
57. Wang, C.; Wang, S.; Bo, L.; Zhu, T.; Yang, X.; Zhang, L.; Jiang, D.; Chen, H.; Huang, S. Synthesis, crystal structures and NIR luminescence properties of binuclear lanthanide Schiff Base complexes. Inorg. Chem. Commun. 2017, 85, 52-55. [CrossRef]

58. Guo, M.; Xu, Y.; Wu, J.; Zhao, L.; Tang, J. Geometry and magnetic interaction modulations in dinuclear Dy2 single-molecule magnets. Dalton Trans. 2017, 46, 8252-8258. [CrossRef] [PubMed]

59. Chen, W.-B.; Chen, Y.-C.; Liu, J.-L.; Jia, J.-H.; Wang, L.-F.; Li, Q.-W.; Tong, M.-L. A Piezochromic Dysprosium(III) SingleMolecule Magnet Based on an Aggregation-Induced-Emission-Active Tetraphenylethene Derivative Ligand. Inorg. Chem. 2017, 56, 8730-8734. [CrossRef] [PubMed]

60. She, S.; Su, G.; Wang, B.; Lei, Q.; Yang, Y.; Gong, L.; Liu, B. Two dysprosium(III) based single-molecule magnets derived from the phen (phen =1,10-phenathroline) ligand and different anion ions act as bridging groups. Eur. J. Inorg. Chem. 2017, 2406-2410. [CrossRef]

61. Maniaki, D.; Mylonas-Margaritis, I.; Mayans, J.; Savvidou, A.; Raptopoulou, C.P.; Bekiari, V.; Psycharis, V.; Escuer, A.; Perlepes, S.P. Slow magnetic relaxation and luminescence properties in lanthanide(III)/anil complexes. Dalton Tans. 2018, 47, 11859-11872. [CrossRef]

62. Mylonas-Margaritis, I.; Maniaki, D.; Mayans, J.; Ciammaruchi, L.; Bekiari, V.; Raptopoulou, C.P.; Psycharis, V.; Christodoulou, S.; Escuer, A.; Perlepes, S.P. Mononuclear Lanthanide(III)-Salicylideneaniline Complexes: Synthetic, Structural, Spectroscopic, and Magnetic Studies. Magnetochemistry 2018, 4, 45. [CrossRef]

63. Llunell, M.; Casanova, D.; Girera, J.; Alemany, P.; Alvaréz, S. SHAPE, Continuous Shape Measures Calculation; Version 2.0; Universitat de Barcelona: Barcelona, Spain, 2010.

64. Panagiotopoulos, A.; Zafiropoulos, T.F.; Perlepes, S.P.; Bakalbassis, E.; Masson-Ramade, I.; Kahn, A.; Terzis, A.; Raptopoulou, C.P. Molecular Structure and Magnetic Properties of Acetato-Bridged Lanthanide(III) Dimers. Inorg. Chem. 1995, 34, 4918-4920. [CrossRef]

65. Liu, W.-J.; Li, Z.-Y.; Wei, Z.-Q.; Yue, S.-T. Tetra- $\mu$-acetato-k ${ }^{4} \mathrm{O}: \mathrm{O}^{\prime} ; \mathrm{k}^{3} \mathrm{O}, \mathrm{O}^{\prime}: \mathrm{O}^{\prime} ; \mathrm{k}^{3} \mathrm{O}: \mathrm{O}, \mathrm{O}^{\prime}$-bis$\left[\left(\right.\right.$ acetato-k $\left.\mathrm{k}^{2} \mathrm{O}, \mathrm{O}^{\prime}\right)(1,10-$ phenathroline$\mathrm{k}^{2} \mathrm{~N}, \mathrm{~N}^{\prime}$ )europium(III)]. Acta Crystallogr. Sect. E 2020, 66, m606. [CrossRef]

66. Yang, S.; Li, B.; Qin, Y.; Liu, L.; Chen, Z. Synthesis, Structure, and Magnetic Properties of a Series of Dinuclear Lanthanide Complexes Assembled by Acetate and a Schiff Base Ligand. Z. Anorg. Allg. Chem. 2016, 642, 521-526. [CrossRef]

67. Nakamoto, K. Infrared and Raman Spectra of Inorganic and Coordination Compounds, 4th ed.; Wiley: New York, NY, USA, 1986; pp. 254-257.

68. Bünzli, J.-C.G. On the design of highly luminescent lanthanide complexes. Coord. Chem. Rev. 2015, 293-294, 19-47. [CrossRef]

69. Armelao, L.; Quici, S.; Barigelletti, F.; Accorsi, G.; Bottaro, G.; Cavazzini, M.; Tondello, E. Design of luminescent lanthanide complexes: From molecules to highly efficient photo-emitting materials. Coord. Chem. Rev. 2010, 254, 487-505. [CrossRef]

70. de Bettencourt-Dias, A. Editorial for the Virtual Issue on Photochemistry and Photophysics of Lanthanide Compounds. Inorg. Chem. 2016, 55, 3199-3202. [CrossRef]

71. Marin, R.; Brunet, G.; Muregesu, M. Shining new light on multifunctional lanthanide single-molecule magnets. Angew. Chem. Int. Ed. 2021, 60, 1728-1746. [CrossRef] [PubMed]

72. Thiakou, K.; Bekiari, V.; Raptopoulou, C.P.; Psycharis, V.; Lianos, P.; Perlepes, S.P. Dinuclear lanthanide(III) complexes from the use of di-2-pyridyl ketone: Preparation, structural characterization and spectroscopic studies. Polyhedron 2006, 25, $2869-2879$. [CrossRef]

73. Aguilà, D.; Barrios, L.A.; Velasco, V.; Roubeau, O.; Repollés, A.; Alonso, P.J.; Sesé, J.; Teat, S.J.; Luis, F.; Aromi, G. Heterodimetallic [LnLn'] Lanthanide Complexes: Toward a Chemical Design of Two-Qubit Molecular Spin Quantum Gates. J. Am. Chem. Soc. 2014, 136, 14215-14222. [CrossRef]

74. Langley, S.K.; Vignesh, K.R.; Gupta, T.; Gartshore, C.J.; Rajaraman, G.; Forsyth, C.M.; Murray, K.S. New examples of triangular terbium(III) and holmium(III) and hexagonal dysprosium(III) single molecule toroics. Dalton Trans. 2019, 48, 15657-15667. [CrossRef] [PubMed]

75. Liu, J.-L.; Chen, Y.-C.; Guo, F.-S.; Tong, M.-L. Recent advances in the design of magnetic molecules for use as cryogenic magnetic coolants. Coord. Chem. Rev. 2014, 281, 26-49. [CrossRef]

76. Woodruff, D.N.; Winpenny, R.E.P.; Layfield, R.A. Lanthanide Single-Molecule Magnets. Chem. Rev. 2013, 113, 5110-5148. [CrossRef]

77. Cador, O.; Le Guennic, B.; Pointillart, F. Electro-activity and magnetic switching in lanthanide-based single-molecule magnets. Inorg. Chem. Front. 2019, 6, 3398-3417. [CrossRef]

78. Harriman, K.L.M.; Errulat, D.; Murugesu, M. Magnetic Axiality: Design Principles from Molecules to Materials. Trends Chem. 2019, 1, 425-439. [CrossRef]

79. Zhu, Z.; Guo, M.; Li, X.-L.; Tang, J. Molecular magnetism of lanthanide: Advances and perspectives. Coord. Chem. Rev. 2019, 378, 350-364. [CrossRef]

80. Liddle, S.T.; van Slageren, J. Improving f-element single-molecule magnets. Chem. Soc. Rev. 2015, 44, 6655-6669. [CrossRef]

81. Ungur, L.; Chibotaru, L.F. Strategies toward High-Temperature Lanthanide-Based Single-Molecule Magnets. Inorg. Chem. 2016, 55, 10043-10056. [CrossRef]

82. Gupta, S.K.; Murugavel, R. Enriching lanthanide single-ion magnetism through symmetry and axiality. Chem. Commun. 2018, 54, 3685-3696. [CrossRef] [PubMed] 
83. Guo, F.-S.; Day, B.M.; Chen, Y.-C.; Tang, M.-L.; Mansikkamäki, A.; Layfield, R.A. Magnetic hysteresis up to 80 Kelvin in a dysprosium metallocene single-molecule magnet. Science 2018, 362, 1400-1403. [CrossRef]

84. Vignesh, K.R.; Alexandropoulos, D.I.; Dolinar, B.S.; Dunbar, K.R. Hard versus soft: Zero-field dinuclear Dy(III) oxygen bridged SMM and theoretical predictions of the sulfur and selenium analogues. Dalton Trans. 2019, 48, 2872-2876. [CrossRef]

85. Long, J.; Habib, F.; Chibotaru, L.F.; Murugesu, M. Single-Molecule Magnet Behavior for an Antiferromagnetically SuperexchangeCoupled Dinuclear Dysprosium(III) Complex. J. Am. Chem. Soc. 2011, 133, 5319-5328. [CrossRef] [PubMed]

86. Roy, L.E.; Hughbanks, T. Magnetic Coupling in Dinuclear Gd Complexes. J. Am. Chem. Soc. 2016, 128, 568-575.

87. Riggle, K.; Lynde-Kernell, T.; Schlemper, E.O. Synthesis and X-ray Structures of Ni(II) Complexes of 1-(2-Pyridinyl)ethenone Oxime. J. Coord. Chem. 1992, 25, 117-125. [CrossRef]

88. Kettle, S.F.A. Physical Inorganic Chemistry—A Coordination Chemistry Approach; Oxford University Press: Oxford, UK, 1998; pp. 462-465.

89. CrystalClear; Rigaku: The Woodlands, TX, USA; MSC Inc.: The Woodlands, TX, USA, 2005.

90. Sheldrick, G.M. A short history of SHELX. Acta Crystallogr. Sect. A 2008, 64, 112-122. [CrossRef] [PubMed]

91. Sheldrick, G.M. Crystal structure refinement with SHELXL. Acta Crystallogr. Sect. C 2015, 71, 3-8. [CrossRef] [PubMed]

92. Diamond, Crystal and Molecular Structure Visualization; Version 3.1; Crystal Impact: Bonn, Germany, 2018.

93. Errulat, D.; Marin, R.; Gálico, D.A.; Harriman, K.L.M.; Pialat, A.; Gabidullin, B.; Iikawa, F.; Couto, O.D.D., Jr.; Moilanen, J.O.; Hemmer, E.; et al. A Luminescent Thermometer Exhibiting Slow Relaxation of the Magnetization: Toward Self-Monitored Building Blocks for Next-Generation Optomagnetic Devices. ACS Cent. Sci. 2019, 5, 1187-1198. [CrossRef] [PubMed]

94. Wang, J.; Zakrzewski, J.J.; Zychowicz, M.; Vieru, V.; Chibotaru, L.F.; Nakabayashi, K.; Chorazy, S.; Ohkoshi, S. Holmium(III) molecular nanomagnets for optical thermometry exploring the luminescence re-absorption effect. Chem. Sci. 2021, 12, 730-741. [CrossRef] 